\title{
Genetic Fate Mapping Reveals That the Caudal Ganglionic Eminence Produces a Large and Diverse Population of Superficial Cortical Interneurons
}

\author{
Goichi Miyoshi, ${ }^{1 \star}$ Jens Hjerling-Leffler, ${ }^{1 \star}$ Theofanis Karayannis, ${ }^{1}$ Vitor H. Sousa, ${ }^{1}$ Simon J. B. Butt, ${ }^{1}$ James Battiste, ${ }^{3}$ \\ Jane E. Johnson, ${ }^{3}$ Robert P. Machold, ${ }^{1,2}$ and Gord Fishell ${ }^{1}$ \\ ${ }^{1}$ Smilow Neuroscience Program and the Department of Cell Biology, and ${ }^{2}$ Department of Otolaryngology, Smilow Research Center, New York University \\ School of Medicine, New York, New York 10016, and ${ }^{3}$ Department of Neuroscience, University of Texas Southwestern Medical Center, Dallas, Texas 75390
}

By combining an inducible genetic fate mapping strategy with electrophysiological analysis, we have systematically characterized the populations of cortical GABAergic interneurons that originate from the caudal ganglionic eminence (CGE). Interestingly, compared with medial ganglionic eminence (MGE)-derived cortical interneuron populations, the initiation [embryonic day 12.5 (E12.5)] and peak production (E16.5) of interneurons from this embryonic structure occurs $3 \mathrm{~d}$ later in development. Moreover, unlike either pyramidal cells or MGE-derived cortical interneurons, CGE-derived interneurons do not integrate into the cortex in an inside-out manner but preferentially (75\%) occupy superficial cortical layers independent of birthdate. In contrast to previous estimates, CGE-derived interneurons are both considerably greater in number ( $\sim 30 \%$ of all cortical interneurons) and diversity (comprised by at least nine distinct subtypes). Furthermore, we found that a large proportion of CGE-derived interneurons, including the neurogliaform subtype, express the glycoprotein Reelin. In fact, most CGE-derived cortical interneurons express either Reelin or vasoactive intestinal polypeptide. Thus, in conjunction with previous studies, we have now determined the spatial and temporal origins of the vast majority of cortical interneuron subtypes.

\section{Introduction}

A wide variety of GABAergic interneuron subtypes exist within the mammalian neocortex (Markram et al., 2004). Establishing the contribution of each cortical interneuron subtype to the development of cortical circuits is complicated by the fact that these are assembled before most interneuron subtypes can be identified

\footnotetext{
Received Sept. 11, 2009; revised Nov. 3, 2009; accepted Dec. 5, 2009.

Research in the Fishell laboratory is supported by National Institutes of Health grants (R01NS039007, R01MH071679) and generous support from both the Simons Foundation and New York State through their NYSTEM initiative. G.M. was supported by a grant from the Japan Society for the Promotion of Science. J.H.-L. was funded by a Swedish Brain Foundation (Hjärnfonden) postdoctoral grant and a European Molecular Biology Organization Long-Term Fellowship. S.J.B. was supported by a Long-Term Fellowship from the Human Frontier Science Program Organization. T.K. received support from a Patterson Trust Fellowship. We thank Dr. Vassilis Pachnis for supplying us with the Lhx6 antibody and Dr. Kenneth Baimbridge for his generous gift of parvalbumin antibody. We thank Drs. Chin $\mathrm{Xu}$ and Stewart Anderson for providing us with their Nkx2-1BAC-Cre driver, Dr. Yuchio Yanagawa for the GAD67-EGFPline, Dr. Alexandra Joyner for TK-Cre deleter mice, and Dr. Susan Dymecki for ACTB-Flpe deleter mice and for providing us with homology arms for targeting the R26R locus, and the CAG promoter. We are thankful for the DNA constructs from Drs. Takahiko Matsuda and Connie Cepko (CAGEN and FlpeMyc) and Dr. Kenneth Campbell (Dlx5/6-CrelRESEGFP). We also thank Dr. Rafael Yuste for his suggestions in making our nomenclature better conform to that proposed by the Petilla Convention. We appreciate Lihong Yin for technical help in genotyping. Finally, we are greatly appreciative to all of the Fishell laboratory members for their support and input on this work, especially Elsa Rossignol and Renata Batista-Brito.

${ }^{*}$ G.M. and J.H.-L. contributed equally to this manuscript.

Correspondence should be addressed to Gord Fishell, Smilow Neuroscience Program and the Department of Cell Biology, Smilow Research Center, New York University School of Medicine, 522 First Avenue, New York, NY 10016. E-mail: fisheg01@nyumc.org.

S. J. B. Butt's present address: Interneuron Development Group, Department of Cellular \& Molecular Neuroscience, Burlington Danes Building, Hammersmith Hospital Campus, Imperial College London, 160 Du Cane Road, London W12 ONN, UK.

DOI:10.1523/JNEUROSCI.4515-09.2010

Copyright $\odot 2010$ the authors $\quad 0270-6474 / 10 / 301582-13 \$ 15.00 / 0$
}

by their mature properties. The solution to this conundrum appears to lie in the growing body of evidence suggesting that the subtype identity of a given interneuron can be predicted by its place and time of origin (Xu et al., 2004; Butt et al., 2005; Wonders and Anderson, 2006; Flames et al., 2007; Fogarty et al., 2007; Ghanem et al., 2007; Miyoshi et al., 2007). Using this developmental strategy, it should be possible to elucidate how individual interneuron subtypes are integrated into the cortical network. Cortical interneurons, at least in rodents, are born within the ventral telencephalon and only subsequently migrate up into the cortex (Anderson et al., 1997). The embryonic ventral telencephalon is characterized by three morphologically distinct progenitor zones, the lateral, medial, and caudal ganglionic eminences (LGE, MGE, and CGE) (Corbin et al., 2001; Flames et al., 2007; Ghanem et al., 2007) (see Fig. 1C). In vivo fate mapping indicates that the MGE and CGE but not the LGE are the primary sources of cortical interneurons (Wichterle et al., 2001; Nery et al., 2002; Butt et al., 2005). The interneurons generated from each of these structures comprise distinct subtypes, with basket and Martinotti interneurons being MGE-derived and the bipolar populations arising from the CGE (Xu et al., 2004; Butt et al., 2005). These studies have suggested that the vast majority of interneurons $(85 \%)$ are derived from the MGE, while the remainder arises from the CGE.

It has been shown that cortical interneurons, like pyramidal neurons (Angevine and Sidman, 1961), are largely generated in an inside-out layering pattern within the neocortex (Miller, 1985; Fairén et al., 1986; Hammond et al., 2004; Yozu et al., 2004; Rymar and Sadikot, 2007). We have previously shown that this is 
indeed the case for MGE-derived interneurons (Miyoshi et al., 2007). In addition, except for the fast-spiking basket cells, most of the MGE-derived interneuron subtypes were shown to have distinct temporal origins (Miyoshi et al., 2007). To further extend our understanding of the temporal origins of cortical interneurons, we established an inducible genetic fate mapping strategy to examine the CGE-derived populations.

This analysis revealed that CGE-derived interneurons target superficial cortical layers regardless of their birthdate. In addition, we found that a large proportion of interneuron subtypes, which had not been previously recognized to be derived from the CGE, express the glycoprotein Reelin. Among the more intriguing Reelin-expressing subtypes originating from the CGE are the late-spiking neurogliaform cells, whose embryonic origins had not been determined previously. In total, we found that the CGEderived population comprises $\sim 30 \%$ of all cortical interneurons, approximately double the number that has been previously reported (Xu et al., 2004; Butt et al., 2005). Moreover, it is comprised by a much larger diversity of subtypes than would have been expected from previous analyses.

\section{Materials and Methods}

Mouse mutants. In our previous fate mapping study (Miyoshi et al., 2007), we used the $Z / E G$ reporter, driven under the regulation of a CAG hybrid promoter (Niwa et al., 1991). While this reporter has higher levels of enhanced green fluorescent protein (EGFP) expression in P21 cortical interneurons compared with $R 26 R$ reporter lines (Soriano, 1999; Srinivas et al., 2001), it suffers from a relatively low level of recombination efficiency. To combine the advantages of the R26R reporter with the high expression levels of the $Z / E G$ reporter, we inserted a CAG hybrid promoter (Niwa et al., 1991) $5^{\prime}$ adjacent to the splice acceptor cassette (Zong et al., 2005; Farago et al., 2006) to boost the endogenous R26R promoter (supplemental Fig. 5, available at www.jneurosci.org as supplemental material). This R26R CAG-boosted EGFP (RCE) reporter has two stop cassettes (RCE:dual), each of which can be removed independently by the Cre or Flpe site-specific recombinases, respectively (Branda and Dymecki, 2004; Miyoshi and Fishell, 2006). By removing one of the stop cassettes using a germline deleter strain with either TK-Cre (Bai et al., 2002) or hActB-Flpe (Rodríguez et al., 2000), we generated a single stopcassette EGFP reporter (RCE:loxP or RCE:FRT) (supplemental Fig. 5, available at www.jneurosci.org as supplemental material). We confirmed that this $R C E$ reporter is active in all cortical interneuron subtypes when the RCE:FRT is used in combination with a Dlx5/6-Flpe driver (supplemental Fig. 1, available at www.jneurosci.org as supplemental material).

For generating a Dlx5/6-Flpe driver line (supplemental Fig. 1, available at www.jneurosci.org as supplemental material), a FlpeMyc cDNA fragment (gift from Dr. Connie Cepko, Harvard Medical School, Cambridge, MA) was placed downstream of the intergenic enhancer region between Dlx5 and Dlx6 (id6/id5) (Zerucha et al., 2000), together with a core promoter (Stenman et al., 2003) and a chimeric intron sequence (AfIII fragment from pCI vector, Promega). An SV40 polyA cassette was used to terminate transcription. This construct was linearized and the bacterial backbone was eliminated with Sall enzyme, and then injected into blastocysts (Skirball transgenic facility, New York University School of Medicine).

Repository stock numbers at Jackson Laboratories for the lines we have generated are as follows: Dlx5/6-Flpe (\#10815), RCE:FRT (\#10812), RCE:loxP (\#10701) and RCE:dual (\#10675).

In vivo fate mapping. Male mouse mutants for Mash1BAC-CreER (heterozygous or homozygous) (Battiste et al., 2007) and RCE:loxP (homozygous) were crossed to Swiss Webster females for inducible genetic fate mapping studies of the CGE. Four milligrams of tamoxifen was administered between noon and 2:00 P.M. at embryonic day 9.5 (E9.5), E10.5, E12.5, E14.5, E16.5 and E18.5. For the intersectional fate mapping of CGE-derived GABAergic lineages, we used males carrying homozygous Mash1BAC-CreER and RCE:dual and crossed them with Dlx5/6-Flpe females, and tamoxifen administration was performed at E16.5.
Histology and cell count. For analyzing the molecular expression profiles and layering of fate-mapped interneurons, the somatosensory barrel cortex in three postnatal day 21 (P21) brains was analyzed using immunohistochemistry (E12.5: $n=1243$, E14.5: $n=3005$, E16.5: $n=4141$, E18.5: $n=2528)$. Immunohistochemistry on $12 \mu \mathrm{m}$ thickness cryosections was performed as described previously (Miyoshi et al., 2007). To assess the size of the four nonoverlapping interneuron populations (see Fig. $4 B$ ), we have performed either PV (parvalbumin)/VIP (vasoactive intestinal polypeptide)/EGFP or SST (somatostatin)/Reelin/ EGFP triple stainings on P21 brains from mice with Dlx5/6-Flpe and $R C E$ :FRT alleles. A total of 1604 EGFP-expressing cells from three brains were analyzed.

Antibodies were used at the following concentrations: mouse antiNkx2.1 (TTF-1) (1:200; PROGEN), rabbit anti-Lhx6 (1:1000; a gift from Dr. Vassilis Pachnis, Medical Research Council National Institute for Medical Research, London, UK), rabbit anti-Pax6 (1:1000; Covance), mouse anti-Mash1 (1:1000; BD PharMingen), mouse anti-Ki67 (1:1000; BD PharMingen), guinea pig anti-Six3 (1:1000; Covance), mouse antiCoupTFII (1:500; Perseus Proteomics), rabbit anti-GFP (1:2000; Invitrogen), rat anti-GFP (1:2000; Nacalai Tesque), goat anti-GFP (1:2000; Rockland), mouse anti-parvalbumin (1:1000; Sigma), guinea pig antiparvalbumin (1:1000; a gift from Dr. K. Baimbridge, University of British Columbia, BC, Canada) rat anti-somatostatin (1:500; Millipore Bioscience Research Reagents), rabbit anti-somatostatin (1:1000; Millipore Bioscience Research Reagents), rabbit anti-Neuropeptide Y (1:500; ImmunoStar), rabbit anti-vasoactive intestinal polypeptide (1:500; ImmunoStar), mouse anti-calretinin (CR) (1:1500; Millipore Bioscience Research Reagents), rabbit anti-calretinin (1:1500; Millipore Bioscience Research Reagents), mouse anti-Reelin (CR50) (1:500; MBL). Secondary antibodies conjugated with Alexa Fluoro dyes 488, 594 or 680 (Invitrogen) or AMCA (Jackson Immunoresearch) raised from the same host used for blocking serum were chosen for signal visualization. Fluorescent images were captured using a cooled-CCD camera (Princeton Scientific Instruments) using MetaMorph software (Universal Imaging). One-way ANOVA with Bonferroni post hoc test was used to detect differences in marker immunolabeling between cell cohorts arising from different developmental time points.

Acute in vitro cortical slice electrophysiology and morphological reconstruction. Whole-cell patch-clamp electrophysiological recordings were performed on EGFP-expressing cells in acute brain slices prepared from P14-P21 animals as previously described (Miyoshi et al., 2007), with the exception that biocytin, instead of Lucifer yellow, was used in the intracellular solution for filling the cells. Briefly, animals were deeply anesthetized, decapitated and the brain was quickly removed and transferred to ice-cold physiological Ringer's solution of the following composition (mM): $125 \mathrm{NaCl}, 2.5 \mathrm{KCl}, 25 \mathrm{NaHCO}_{3}, 1.25 \mathrm{NaH}_{2} \mathrm{PO}_{4}, 1 \mathrm{MgCl}_{2}, 2 \mathrm{CaCl}_{2}$ and 20 glucose. The brain was then fixed to a stage and $250 \mu \mathrm{m}$ slices was cut on a vibratome (Vibratome $3000 \mathrm{EP}$ ). Slices were then individually transferred into an incubation chamber containing oxygenated Ringer's solution at room temperature for a minimum period of $1 \mathrm{~h}$ before recordings. During recording, slices were continually perfused with oxygenated Ringer's of the same composition. Whole-cell tight seal recordings were made from randomly selected EGFPpositive neurons located in all layers of the somatosensory cortex. Fifteen cells from E12.5 and 21 cells from E16.5 were not selected randomly and were excluded from the temporal profile of fate-mapped interneurons in Figure 5F. Patch electrodes were made from borosilicate glass (resistance 5-8 M $\Omega$, Harvard Apparatus) and filled with a solution containing (in mM): $128 \mathrm{~K}$-gluconate, $4 \mathrm{NaCl}, 0.3 \mathrm{GTP}, 5 \mathrm{ATP}, 0.0001 \mathrm{CaCl}_{2}, 10$ HEPES, 1 glucose, and $5 \mathrm{mg} / \mathrm{ml}$ biocytin (Sigma). All recordings were performed in current-clamp mode (Axoclamp 2B, Molecular Devices) and analyzed off-line in Clampfit version 9.2. Passive membrane properties were ascertained shortly after rupturing the patch and periodically during the course of the experiments to ensure that there was no significant deterioration in the health of the cell.

For post hoc morphological and immunohistochemical reconstruction, brain slices were fixed on ice for $1 \mathrm{~h}$ with $4 \%$ formaldehyde in PBS, rinsed with PBS, and incubated with primary antibodies at suitable concentrations in $1.5 \%$ donkey serum with $0.1 \%$ Triton $\mathrm{X}-100$ 
for two to three nights at $4^{\circ} \mathrm{C}$. After several washes with PBS, marker expressions were visualized by suitable secondary antibodies conjugated with Alexa fluorophores by incubating in the same solution used for primary antibody reaction overnight at $4^{\circ} \mathrm{C}$. To better visualize cell morphology, Alexa Fluor 488-conjugated streptavidin (4 $\mu \mathrm{g} / \mathrm{ml}$, Invitrogen) was also included in this step. After the fluorescent imaging, the cells were developed using the ABC-peroxidase/ $\mathrm{DAB}$ reaction with the Vectastain Elite kit (Vector Laboratories), and subsequent tracing was performed using a Neurolucida set-up (MBF Bioscience).

Analysis of intrinsic properties. We used a similar $500 \mathrm{~ms}$ stimuli protocol as previously reported (Kawaguchi, 1995; Miyoshi et al., 2007). In brief: a ramp protocol $[100 \mathrm{pA} / 3 \mathrm{~s}$ from resting membrane potential (RMP)], followed by a round of $100 \mathrm{pA}$ steps to determine the approximate current injection needed to cause the cell to fire. The actual current injection necessary for threshold was determined with finer steps (5-20 $\mathrm{pA}$ ) around that value. After this, both negative and positive current was injected to determine the intrinsic firing properties of the interneurons. Using these protocols we then analyzed the cells for 13 different parameters (see also Table 4): RMP, which was measured momentarily after breakthrough into the cell; input resistance $\left(R_{\text {in }}\right)$, which was obtained by dividing the resulting hyper-polarization with the injected current at a current injection that was $1 / 4$ of the one needed to bring the cell to -100 $\mathrm{mV}$; membrane constant (Tau), using the same trace as for $R_{\text {in }}$ we applied the fitting function in Clampfit 9.2 (Axon); spike threshold, which was obtained using the first spike fired at either a ramp protocol (100 pA over $3 \mathrm{~s}$ ) or at the lowest current injection (within 5-20 pA step) that elicited firing. The following parameters were measured from the threshold spike: spike height; spike width (at half of the spike height); afterhyperpolarization (AHP) $T_{\text {nadir }}$, the time from spike threshold to lowest point of the AHP, when there was a biphasic AHP we measured the value for the bigger component, upon burst firing at threshold we used the value from the initiation of the last spike in the train to the lowest point of the following AHP; AHP amplitude ( $\mathrm{mV})$, the difference in voltage from spike initiation to lowest point of AHP; delay to spike, the time from onset of current step to spike initiation at threshold stimulation; Max firing frequency, the average frequency $(\mathrm{Hz})$ elicited by current injection that does not cause major spike height loss or failing of the cell [for fast-adapting cells (fADs) the frequency was calculated on the initial part of the stimuli before failing rather than throughout the entire $500 \mathrm{~ms}$ ); Adaptation, calculated as (f1$\mathrm{f} 2) / \mathrm{f} 1 \%$ where $\mathrm{f} 1$ is the frequency of the first $100 \mathrm{~ms}$ at maximum firing frequency and $\mathrm{f} 2$ is the last $100 \mathrm{~ms}$ of the $500 \mathrm{~ms} \mathrm{stimuli} ; I_{\mathrm{h}} / \mathrm{sag}$, calculated as the voltage difference of the lowest point and the endpoint of a hyper-polarization to $-100 \mathrm{mV}$. We also checked for subthreshold oscillations; if $>70 \%$ of any subtype consistently showed oscillations we classified it as being present (Y) and if $<25 \%$ exhibited this property we denoted it as a negative $(\mathrm{N})$. Two-tailed Student's $t$ test was used to detect morphological differences between LS-cell types.

\section{Results}

\section{A genetic strategy for fate mapping temporally distinct} cohorts derived from the CGE

We have previously estimated that CGE-derived interneurons comprise $\sim 15 \%$ of all cortical interneurons (Nery et al., 2002; Butt et al., 2005). However, this estimate was compromised by the fact that when we undertook this study we had no systematic method for analyzing the full extent of this population. To achieve this goal, we took advantage of the fortuitously restricted expression of a specific transgenic founder line, Mash1BAC-CreER (Fig. 1A, left) (Battiste et al., 2007). In this driver line, a tamoxifen inducible form of the site-specific recombinase Cre (CreER), is expressed under the regulation of a $~ 300 \mathrm{~kb}$ DNA fragment (Parras et al., 2007) that includes cis-regulatory elements of the basic helix-loop-helix type transcription factor Mash1 (Ascl1) (Johnson et al., 1990; Guillemot and
Joyner, 1993). Mash1 is normally strongly expressed throughout the subventricular zone of the entire ventral telencephalon (Fig. $1 E, F)$ (Guillemot and Joyner, 1993; Casarosa et al., 1999; Horton et al., 1999; Fode et al., 2000; Parras et al., 2002; Yun et al., 2002). However, we were able to identify a driver line that, when paired with a Cre-dependent EGFP reporter line we have generated (RCE:loxP; Fig. 1A, left; supplemental Fig. 5, available at www. jneurosci.org as supplemental material), broadly labeled Mash1expressing cells in the CGE and LGE, but strikingly, did not label cells within the MGE (Fig. $1 B$, compare with $C$ showing panGABAergic labeling with the method in $A$, right; for details of our Dlx5/6-Flpe transgenic driver and the RCE:FRT reporter, see supplemental Figs. 1, 5, available at www.jneurosci.org as supplemental material, and Materials and Methods). This is presumably due to positional effects at the site of transgene insertion. In our previous work (Wichterle et al., 2001), we found that, at least at E13.5, the LGE does not generate appreciable numbers of cortical interneurons. We therefore reasoned that we could take advantage of this particular Mash1BAC-CreER driver to selectively fate map the CGE-derived cortical interneurons arising from different developmental time points.

We first characterized the cell populations labeled by our fate mapping approach through short-term analysis. To accomplish this, we administered $4 \mathrm{mg}$ of tamoxifen to a pregnant mother carrying E10.5 Mash1BAC-CreER and RCE:loxP double transgenic embryos and analyzed the resulting labeled cell populations at E11.5 (Fig. 1B,D-H). Consistent with our initial assessment (Fig. 1B), the majority of labeling was observed within the LGE (Fig. 1E) and CGE (Fig. 1F) where Mash1 is strongly expressed in the progenitor domains. In contrast, virtually no cells were observed within the Nkx2-1expressing MGE territory (Fig. 1D).

Previous analysis indicates that $C r e E R$-mediated reporter recombination initiates $6 \mathrm{~h}$ after tamoxifen administration and peaks within $\sim 24$ h (Zervas et al., 2004). Hence, this inducible genetic fate mapping strategy allows us to label cells approximately within a 1-d time window. Furthermore, Mash1 is expressed within subventricular zone cells that are fated to become postmitotic and leave the progenitor domain quickly (Casarosa et al., 1999; Bertrand et al., 2002). Consistent with this, $1 \mathrm{~d}$ after tamoxifen administration, only a few cells within the genetically fate mapped population maintained high-levels of Mash1 expression (Fig. 1F,G). Conversely, those Mash1-expressing cells that did express EGFP, did so only at very low levels (Fig. 1G, arrowheads), strongly suggesting that the removal of the stop cassette in the reporter line had just occurred in this population. Indeed, $1 \mathrm{~d}$ after tamoxifen administration, very few of the labeled cells located proximal to the ventricle coexpressed the proliferation marker Ki67 (Kill, 1996) (Fig. 1H, inset). Two days after tamoxifen administration, no EGFP-expressing fate-mapped cells expressed Ki67 (Fig. 1I). Four days later (E14.5) all the fate-mapped cells were in the mantle zones (supplemental Fig. $2 B$, available at www.jneurosci.org as supplemental material). In comparison, a parallel analysis using a Nestin-CreER driver (Balordi and Fishell, 2007), which targets self-renewing progenitors in the ventricular zone, resulted in many labeled cells remaining in the ventricular zone $2 \mathrm{~d}$ after tamoxifen administration (Fig. $1 J$ ).

Together, these data demonstrate that by combining the Mash1BAC-CreER driver with the RCE:loxP reporter, and by administrating tamoxifen at different time points, we are able to fate map temporally distinct cohorts derived from the LGE and the CGE. 
A
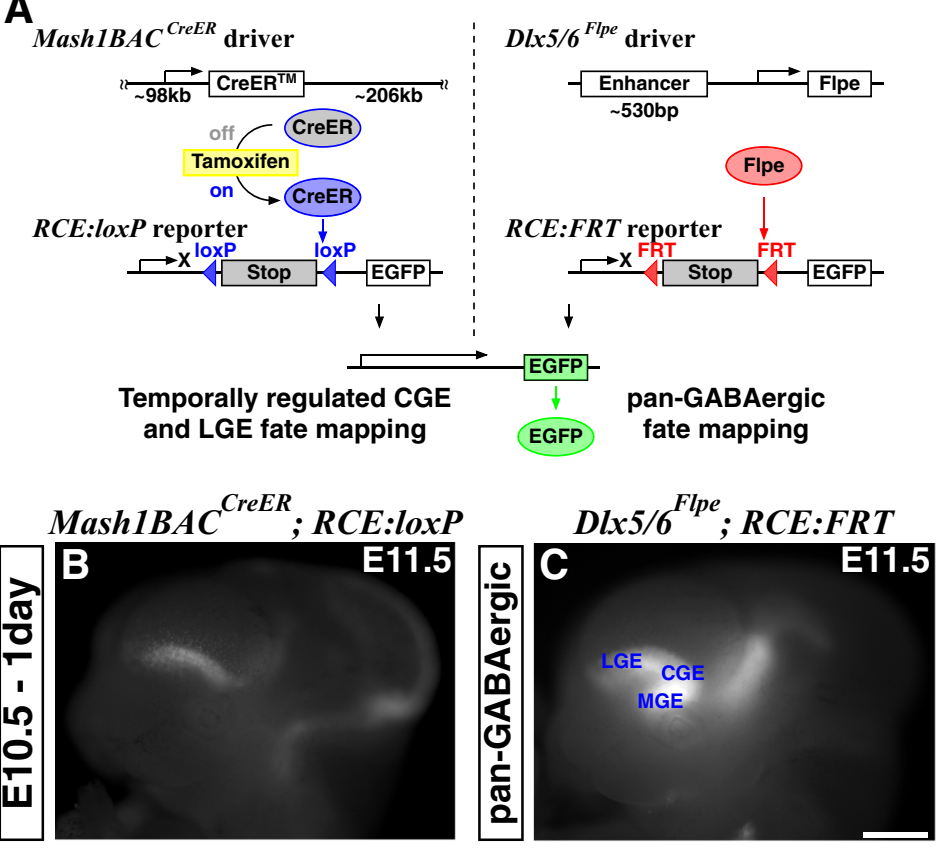

CGE and LGE fate mapping: Mash1BAC ${ }^{\text {CreER }} ; \boldsymbol{R C E}: \operatorname{loxP}$
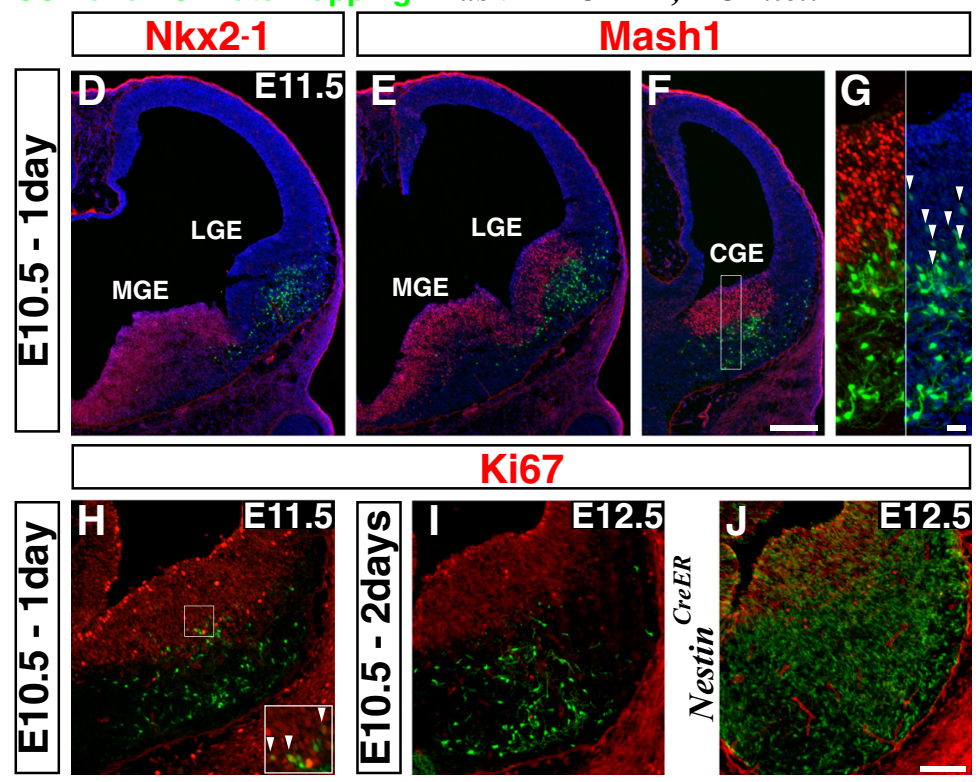

Figure 1. An inducible genetic strategy for fate mapping temporally distinct interneuron cohorts derived from the CGE. $A_{t}$ Schematics of an inducible genetic fate mapping strategy for (GE- and LGE-derived cells (left), and a method for fate mapping the entire GABAergic population in the forebrain (right). Left, By combining a Mash1BAC-CreER driver with an RCE:loxP reporter, Mash1-expressing cells in the CGE and LGE can be labeled at the desired time point by administration of tamoxifen. Within 6-24 h of tamoxifen administration, CreER is activated and removes the stop cassette in the RCE:loxP reporter by recombining the flanking loxP sites, resulting in permanent EGFP labeling of the cells expressing Mash1 in the CGE and LGE at this time. Right, Our D/x5/6-F/pe driver expresses the site-specific recombinase F/pe under the regulation of the intergenic enhancer between $D / x 5$ and D/x6 (id6/id5). By combining this line with the RCE:FRT reporter, which possesses a stop cassette flanked by FRT sites, the entire forebrain GABAergic population is labeled with EGFP. Note that both $R C$ reporters (RCE:loxP and RCE:FRT) were generated from a single dual-stop reporter (RCE:dual; see supplemental Fig. 5, available at www.jneurosci.org as supplemental material). $\boldsymbol{B}$, EGFP expression in E11.5 whole mount brains after E10.5 tamoxifen administration. Note that EGFP expression is excluded from the MGE (compare with C). In addition to the labelings in the LGE and (GE, EGFP expression was observed in the thalamus and mid/hindbrain regions. C, D/x5/6-Flpe directed pan-GABAergic EGFP labeling in the forebrain region is observed throughout the MGE, CGE and LGE, as well as in the thalamus at E11.5. D-G, Coronal telencephalic sections of $\boldsymbol{B}$. D, As suggested by whole mount analysis (B), EGFP labeling is excluded from the MGE, which is marked by Nkx2-1 expression. $E$, $F$, Although Mash1 is normally expressed throughout the entire ventral forebrain progenitor zone $(\boldsymbol{E}, \boldsymbol{F})$, this particular founder does not recombine the reporter in the MGE. This allowed us to specifically label the cells in the CGE $(\boldsymbol{F})$ and the $L G E(\boldsymbol{E})$. $\boldsymbol{G}$, Higher magnification of the (GE progenitor domain of $\boldsymbol{F}$. All of the EGFP-positive cells coexpressing Mash 1 (arrowheads) show only low levels of EGFP expression, suggesting that the removal of the stop cassette in the reporter has occurred only recently in these cells. $\boldsymbol{H}$, A section adjacent to $\boldsymbol{F}$. Very few proliferating cells
The CGE starts producing cortical interneurons at E12.5

The earliest time point where tamoxifen administration reliably resulted in cell labeling was E9.5 (data not shown). However, before E12.5 (i.e., E10.5; Fig. 1F), tamoxifen administration only resulted in fate-mapped cells contributing to the ventral telencephalon (see detailed characterizations in supplemental Fig. 2, available at www.jneurosci.org as supplemental material). This stands in stark contrast to our previous analysis, where we found that MGE-derived cortical interneurons could be labeled extensively after E9.5 tamoxifen administration (Miyoshi et al., 2007).

These observations suggest that the generation of cortical interneurons in the CGE is initiated later than in the MGE, and thus we set out to determine the time course of interneuron production from this structure. One day after E12.5 tamoxifen administration, we observed cell labeling in the CGE (Fig. 2A; supplemental Fig. 3A, available at www.jneurosci.org as supplemental material), as well as a small population within the septum (data not shown). At this stage a portion of MGEderived cells migrate dorsally through the CGE (Butt et al., 2005). These cells express Lhx6, a Lim-domain containing homeodomain transcription factor that is a downstream target of Nkx2-1 (Sussel et al., 1999; Butt et al., 2008; Du et al., 2008) and whose expression is retained in MGEderived cortical interneurons as they mature (Fogarty et al., 2007). We thus confirmed the CGE-origin of our E12.5 labeled population by demonstrating that they uniformly lack Lhx6-expression (Fig. $2 B, C)$.

Two days after tamoxifen administration at E12.5, some cells were observed within the cortex (most prominently in the caudal regions), and displayed morphologies indicative of active migration (Fig. 2D,E). Consistent with our acute analysis, the vast majority of these fatemapped cells in the cortex did not coexpress Lhx6, further indicating a CGE-origin (Fig. 2E). While these cells are tangentially migrating through the cortex, they use the known two pathways in the marginal

(Ki67-positive) are labeled $1 \mathrm{~d}$ after tamoxifen administration (arrowheads in inset). $I$, Two days after tamoxifen administration, no fate-mapped cells coexpress Ki67.J, By comparison, many of the cells fate mapped using a NestinCreER driver line continue to proliferate $2 \mathrm{~d}$ after tamoxifen administration. Scale bars: $\boldsymbol{B}, \boldsymbol{C}, 500 \mu \mathrm{m} ; \mathbf{D}-\boldsymbol{F}, 200 \mu \mathrm{m} ; \boldsymbol{G}$, $20 \mu \mathrm{m} ; \boldsymbol{H}-J, 100 \mu \mathrm{m}$ 
and the intermediate/subventricular zones (Marín and Rubenstein, 2003; Kriegstein and Noctor, 2004). Interestingly, more than half $(58.8 \%)$ of the fate-mapped cells in the cortex expressed low levels of Mash1 (Fig. 2F, same section from Fig. $2 D$; note that the expression levels are much higher in the ventral telencephalon). We suspected that this resulted from the selective maintenance of Mash1 expression within the CGE-derived population. To test this hypothesis, we examined Nkx2-1BAC-Cre driver (Xu et al., 2008) on an RCE:loxP reporter background, to label the majority of MGE-derived populations. Only very few (9.0\%) of MGEderived cells in the cortex coexpressed Mash1 (Fig. 2H) suggesting that the expression of low levels of Mash1 in migrating cortical interneurons is largely a hallmark of the CGE-derived population. The transcription factor CoupTFII (Nr2f2) has previously been shown to be strongly expressed in the CGE progenitor domain but only in small portions of the LGE and MGE (Kanatani et al., 2008; WilliMonnerat et al., 2008). Consistent with this, we found that CoupTFII is expressed in most fate-mapped interneurons from the CGE (84.6\%) (Fig. 2G) but in very few MGE-derived interneurons (10.1\%) (Fig. 2I). Hence, although CoupTFII is presently considered to be the gene whose expression is most confined to the CGE-derived cortical interneurons, our Mash1BAC-CreER fate-mapping strategy provided a greater degree of specificity for targeting these lineages. In addition, since CoupTFII is largely excluded from the LGE, this also provides further support that the cortical interneurons we fate map are CGE rather than LGE-derived. In conclusion, our results demonstrate that the CGE starts producing cortical interneurons a few days later than the MGE, and that the expression profiles of transcription factors are distinct in MGE- and CGE-derived interneurons at E14.5.

The peak production of cortical interneurons from the CGE is delayed relative to the $\mathrm{MGE}$

To fully delineate the temporal profiles of CGE-derived cortical interneurons, we administered tamoxifen to mice carrying the Mash1BAC-CreER driver and RCE:loxP reporter at E14.5, E16.5, and E18.5. Similar to the earlier time points, acute cell labeling was overwhelmingly restricted to the LGE and CGE regions, where Nkx2-1 is not expressed (supplemental Fig. 3, available at www.jneurosci.org as supplemental material). However, unlike the previous stages analyzed (E10.5 and E12.5 fate mapping), a small number of labeled cells were observed within the cortex $1 \mathrm{~d}$ after tamoxifen administration (most prominently in caudal regions of the cortex), especially at the E16.5 time point (supplemental Fig. 3E,F, available at www.jneurosci.org as supplemental material). As Mash1 is known to be expressed at low levels in pyramidal neuron progenitors (Britz et al., 2006), we confirmed that at P21, the observed EGFP-labeling is restricted to interneurons and excluded from the pyramidal cell population, based on the morphologies of the labeled cells (Fig. $3 A$ ). Furthermore, when we used the Mash1BAC-CreER driver in combination with a $D l x 5 / 6-F l p e$ driver (Fig. $1 A$, right, $1 C$; supplemental Figure 1, available at www.jneurosci.org as supplemental material) and our RCE:dual reporter (supplemental Fig. 5, available at www.jneurosci.org as supplemental material) (where the expression of EGFP from the reporter requires the removal of two stop cassettes that are excised by Cre and Flpe, respectively), the cortical cell labeling was equivalent to that observed using our primary genetic labeling strategy (i.e., Mash1BAC-CreER; RCE:loxP, compare supplemental Fig. $3 F, G$, available at www.jneurosci.org as supplemental material). Together, these results confirm that 
A P21 Somatosensory barrel field
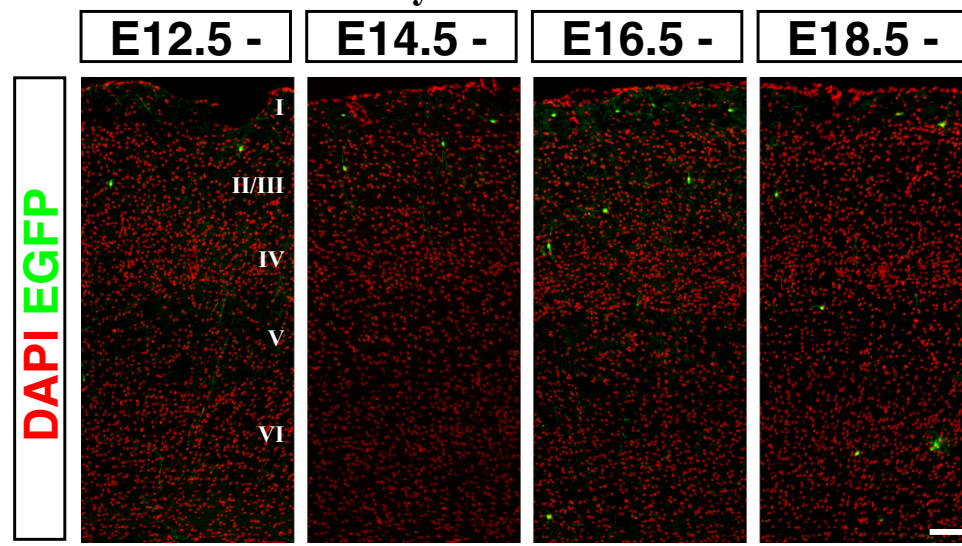

B

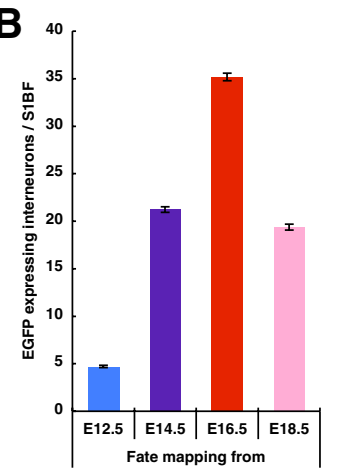

C

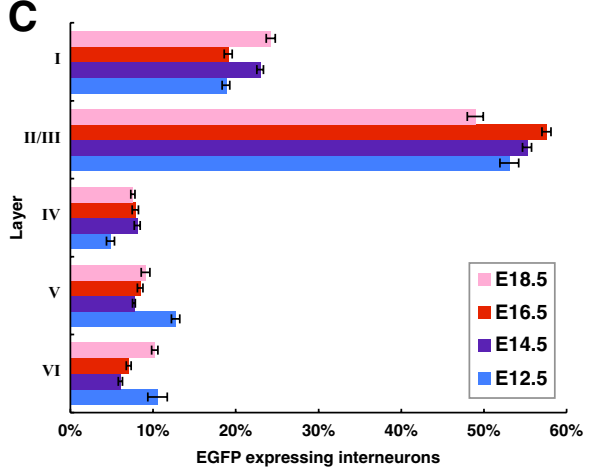

Figure 3. CGE-derived interneurons integrate preferentially into superficial cortical layers independent of their birthdates with peak production occurring at E16.5. A, Representative pictures within the P21 somatosensory cortex showing fate-mapped interneurons from four embryonic time points (E12.5, E14.5, E16.5 and E18.5). Cortical layering was revealed by DAPI nuclear counterstaining (pseudo colored in red). $B$, A quantification of the cell numbers at P21 from four embryonic fate-mapping time points. The largest numbers of cortical interneurons were fate mapped from the E16.5 time point. $\boldsymbol{C}$, The laminar distributions of fate-mapped interneurons from four embryonic time points (E12.5, E14.5, E16.5, and E18.5) were analyzed. At all time points examined, CGE-derived interneurons were found to preferentially occupy superficial layers in the P21 cortex. Error bars, SEM. Scale bar, $100 \mu \mathrm{m}$. al., 2007). The temporal dynamics of the generation of interneurons from the MGE and CGE are strikingly different in terms of their time of onset (Fig. 2D) and peak production (Fig. 3B). To assess whether CGEderived cortical interneurons populate particular cortical laminae in accordance with their birthdate, we analyzed the cortical layering of CGE-derived interneurons fate mapped from four time points: E12.5, E14.5, E16.5 and E18.5 (Fig. 3A). In the mature cortex, $\sim 20 \%$ of the cells reside in layer I, and $\sim 55 \%$ of the cells are located in layers II and III (Fig. 3C). To our surprise, we discovered that, regardless of when they are generated, CGE-derived interneurons preferentially target the superficial layers of the cortex (Fig. 3C).

\section{CGE-derived Reelin- and VIP- expressing populations constitute a large proportion of cortical interneurons}

In the mouse somatosensory cortex, PV, SST, and VIP are expressed in mutually exclusive populations of cortical interneurons (Fig. 4A) (Kubota et al., 1994; Miyoshi et al., 2007). By fate mapping Lhx6-expressing lineages, it has recently been demonstrated that PV- and SSTexpressing interneurons are exclusively derived from the MGE (Fogarty et al., 2007) (Fig. 4A). VIP immunoreactivity does not appear until postnatal stages (Emson et al., 1979) and is entirely confined to the GABAergic population within the neocortex (Rogers, 1992). Consistent our fate mapping of cells over this time period was restricted to GABAergic populations.

Having established that we could reproducibly label distinct cohorts of interneurons derived from the CGE at different embryonic stages, we began to study the temporal profile of their production. To be consistent with our previous studies (Butt et al., 2005; Miyoshi et al., 2007), we characterized the numbers, layering and molecular expression profiles of labeled interneurons at P21 within the somatosensory barrel field $(\mathrm{S} 1 \mathrm{BF})$ of the cortex (Fig. 3A). We first analyzed the proportion of CGE-derived interneurons fate mapped from different embryonic time points. Our data indicate that E12.5 represents the earliest stage at which cortical interneurons are generated from the CGE (Figs. 2D, 3B), while the peak of interneuron production appears to occur at E16.5 (Fig. 3B). Hence, both the initiation and peak of interneuron production in the CGE are delayed by 3 d relative to that seen in the MGE (Miyoshi et al., 2007).

CGE-derived interneurons primarily contribute to superficial cortical layers independent of their birthdates

Previous studies have indicated that GABAergic interneurons populate cortical layers in an "inside-out" manner depending on birthdate, similar to pyramidal neurons (Miller, 1985; Fairén et al., 1986). Indeed, our previous study confirmed that MGE-derived interneurons integrate into cortical layers largely in this manner (Miyoshi et with previous observations (Xu et al., 2004; Butt et al., 2005), using an Nkx2-1BAC-Cre driver (Xu et al., 2008) crossed with the $R C E$ :loxP reporter, we confirmed that VIP-expressing interneurons are not derived from the MGE (Fig. 4A; Table 1). By using VIP as a CGE-derived interneuron-specific molecular marker, we analyzed genetically fate-mapped cells and found that around half of this population, particularly in superficial layers, did not express VIP. We therefore searched for other markers and discovered, by using the CR50 antibody (Ogawa et al., 1995), that the glycoprotein Reelin is expressed in a large percentage of CGEderived interneurons (Fig. 4A). We first confirmed that Reelin is expressed exclusively in GABAergic interneurons within the P21 cortex (Fig. 4C,D). This was achieved by comparing Reelin expression to the entire GABAergic cortical interneuron population labeled with EGFP, by combining our Dlx5/6-Flpe driver and $R C E$ :FRT reporter (Fig. $1 A$, right; supplemental Fig. 1, available at www.jneurosci.org as supplemental material). This was also confirmed by using a GAD67-EGFP transgenic line, which targets EGFP expression to most of the GABAergic population (data not shown) (Tamamaki et al., 2003). Most strikingly, at P21, almost all the GABAergic interneurons within layer I expressed Reelin (Fig. 4C,D). In contrast, at P1, Reelin expression was excluded from the GABAergic population (Fig. $4 E, F$ ) but was present in layer I glutamatergic Cajal-Retzius populations (Fig. 4E,F), as has been previously reported (del Río et al., 1995). Consistent with what has been shown by others (del Río et al., 1995; Derer 
and Derer, 1990; Meyer et al., 1998), Reelinexpressing Cajal-Retzius cells disappear by P21. Instead, at this age we observed that Reelin is expressed in a subpopulation of cortical interneurons.

Next we tested whether Reelin expression in GABAergic interneurons was confined to a specific subtype. While Reelin had been previously demonstrated to be expressed in subpopulations of cortical interneurons (Alcántara et al., 1998; Pesold et al., 1998, 1999; Cobos et al., 2005; Cubelos et al., 2008), the specific subtypes expressing this protein have remained unexplored. We found that Reelin was not coexpressed within the PV-expressing interneurons (Table 2) and is very rarely coexpressed with VIP (1.4\%) (Table 2). In contrast, Reelin is coexpressed within many SSTexpressing interneurons (Pesold et al., 1999) (Fig. 4A; Table 2), a population which as noted above is exclusively derived from the MGE (Fogarty et al., 2007). We therefore tested whether any of the Reelin-positive interneurons without SST expression are derived from the MGE. We performed triple labeling comparing SST and Reelin expression to EGFP labeling in MGE-derived interneurons using a transgenic mouse carrying both the Nkx21BAC-Cre driver (Xu et al., 2008) and the $R C E$ :loxP reporter (Fig. 4G; Table 3 ). We found that all of the Reelin-expressing interneurons derived from the MGE coexpress SST (Fig. 4A,G). These data strongly suggest that SST-negative Reelin-expressing interneurons are exclusively derived from the CGE and likely account for a large proportion of the CGE-derived interneurons for which no molecular marker has previously existed (Fig. 4A).

By using Reelin (SST-negative) and VIP as markers specific to CGE-derived interneurons, and combining these with pan-GABAergic labeling (Dlx5/6-Flpe; $R C E: F R T$ ), we found that $\sim 30 \%$ of all cortical interneurons appear to be CGEderived (Fig. 4B). In addition, we found that most of the GABAergic cortical interneurons (95\%) can be accounted for with one of the four nonoverlapping markers of PV, SST, Reelin (without SST), and VIP (Fig. 4A,B). By using these molecular markers to delineate interneuron subpopulations, we have characterized the cortical interneurons fate mapped from four sequential embryonic time points (E12.5, E14.5, E16.5, and E18.5) in Mash1BAC-CreER; RCE:loxP animals (Fig. 5E). As expected, we fate mapped only a small number of PV- and SSTexpressing interneurons, which are known to be MGE-derived subtypes (Fogarty et al., 2007). These data confirm that the Reelin-expressing population arising from the CGE do not include interneurons coexpressing Reelin and SST (Fig. 4A). We
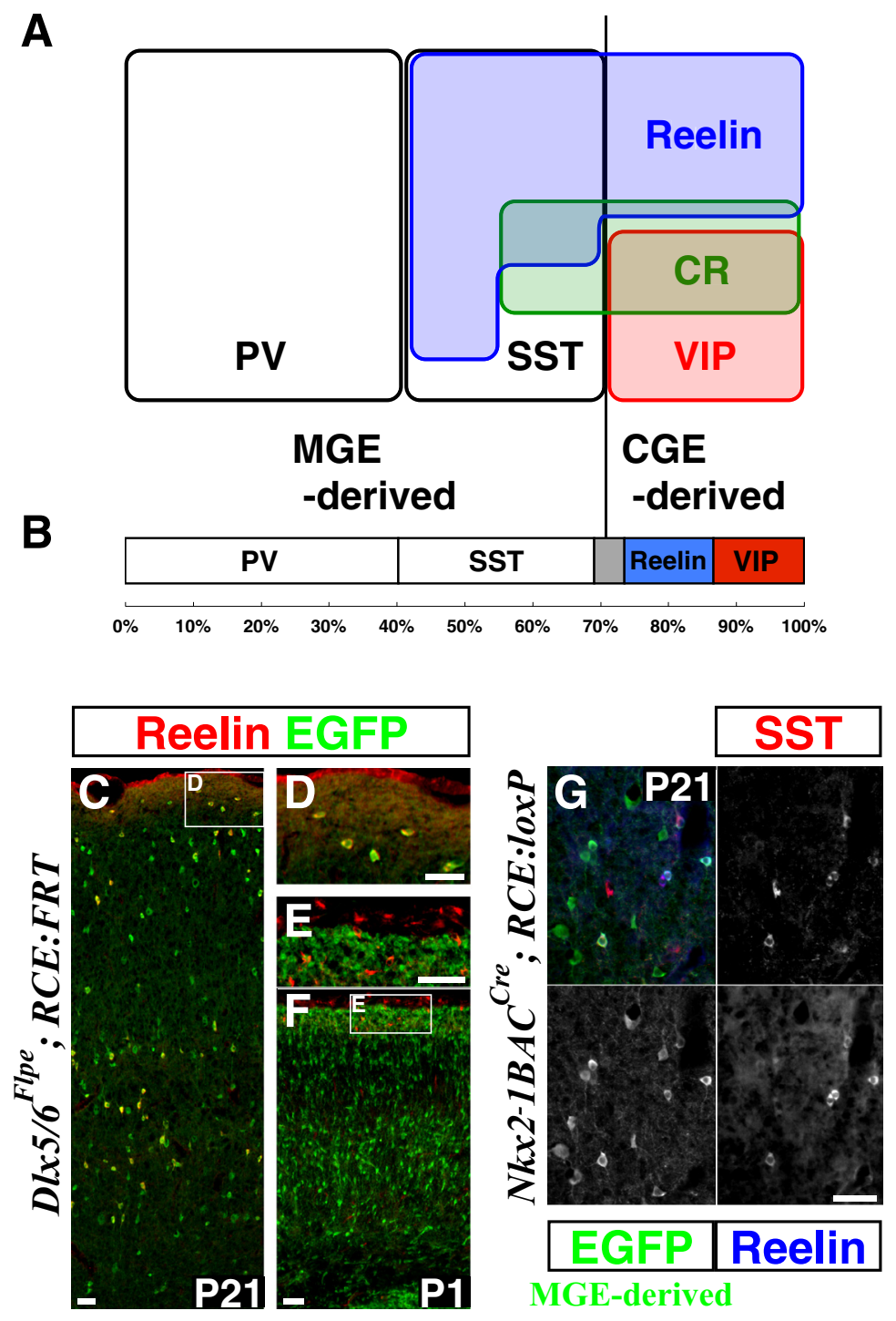

Figure 4. A large proportion of interneurons is derived from the CGE and express either Reelin or VIP. A, Schematic showing the molecular expression profiles of GABAergic interneurons in the P21 somatosensory mouse barrel cortex. PV-, SST-, and VIP-immunopositive populations constitute mutually exclusive interneuron subtypes. PV- and SST-expressing populations are exclusively derived from the Lhx6-expressing MGE lineage (Fogarty et al., 2007). All VIP-expressing interneurons are derived from the (GE (see also Table 1). The MGE gives rise to a population of interneurons that coexpress Reelin and SST, while those Reelin expressing interneurons lacking SST-expression are CGE-derived (Table 3). CR is coexpressed with all markers with the exception of PV. In addition, there appears to be a small population that is solely CR-positive within the CGE-lineage. $\boldsymbol{B}$, Within the total cortical interneuron population labeled with D1x5/6-Flpe driver and RCE:FRT reporter, at least $69.1 \%$ (PV: $40.3 \% \pm 0.90 \%$ and SST: $28.8 \% \% \pm 1.82 \%$ ) are derived from the MGE and at least $26.4 \%$ (Reelin: $13.1 \% \pm 1.03 \%$ and VIP: $13.3 \% \pm 0.28 \%$ ) are derived from the CGE. The gray region represents the $\sim 5 \%$ of all cortical interneurons for which we presently lack any marker. $\mathbf{C}-\boldsymbol{F}$, Reelin expression in the P21 $(\boldsymbol{C}, \boldsymbol{D})$ and P1 $(\boldsymbol{E}, \boldsymbol{F})$ mouse somatosensory cortex. The Reelin-expressing cells are GABAergic interneurons that are marked by EGFP expression from the D/x5/ 6-Flpe driver and RCE:FRT reporter combination. Most of the interneurons in layer I coexpress Reelin $(\boldsymbol{C}, \boldsymbol{D})$. In contrast at $P 1$, none of the Reelin-expressing cells in layer I are GABAergic, but instead are glutamatergic Cajal-Retzius cells $(\boldsymbol{E}, \boldsymbol{F})$. $\boldsymbol{G}$, All of the Reelin-expressing cells derived from the MGE (marked with Nkx2-1BAC-Cre and RCE:IoxP) coexpress SST, suggesting that Reelin-expressing SST-negative interneurons are exclusively derived from the CGE (Table 3). Scale bars, $50 \mu \mathrm{m}$.

Table 1. Interneuron-specific molecular markers in P21 mouse somatosensory cortex: Nkx2.1BAC ${ }^{\text {Cre }}$ x RCE:loxP (MGE fate mapping)

\begin{tabular}{llll}
\hline EGFP + & EGFP $+/$ VIP + & VIP + & Total \\
\hline $81.1 \%$ & $0 \%$ & $18.9 \%$ & 956 cells
\end{tabular}

VIP is never expressed in MGE-derived interneurons, making VIP a specific molecular marker for CGE-derived population. 
Table 2. Interneuron-specific molecular markers in P21 mouse somatosensory cortex: Reelin expression in cortical interneuron subtypes

\begin{tabular}{|c|c|c|c|c|c|c|c|}
\hline $\begin{array}{l}\text { Reelin+ } \\
41.1 \%\end{array}$ & & $\begin{array}{l}\text { Reelin+/PV+ } \\
0 \%\end{array}$ & & & $\begin{array}{l}\mathrm{PV}+ \\
58.9 \%\end{array}$ & & $\begin{array}{l}\text { Total } \\
849 \text { cells }\end{array}$ \\
\hline $\begin{array}{l}\text { Reelin+ } \\
62.4 \%\end{array}$ & & $\begin{array}{l}\text { Reelin }+/ \text { VIP }+ \\
0.9 \%\end{array}$ & & & $\begin{array}{l}\text { VIP }+ \\
36.8 \%\end{array}$ & & $\begin{array}{l}\text { Total } \\
465 \text { cells }\end{array}$ \\
\hline $\begin{array}{l}\text { Reelin }+ \\
23.1 \%\end{array}$ & $\begin{array}{l}\text { Reelin +/SST + } \\
30.8 \%\end{array}$ & $\begin{array}{l}\text { Reelin }+/ C R+ \\
3.0 \%\end{array}$ & $\begin{array}{l}\text { SST+ } \\
14.6 \%\end{array}$ & $\begin{array}{l}\mathrm{CR}+ \\
19.3 \%\end{array}$ & $\begin{array}{l}S S T+/ C R+ \\
4.1 \%\end{array}$ & $\begin{array}{l}\text { Triple+ } \\
5.1 \%\end{array}$ & $\begin{array}{l}\text { Total } \\
493 \text { cells }\end{array}$ \\
\hline
\end{tabular}

Reelin-expressing interneurons were never found to express PV, and are very rarely found to co-express VIP. Reelin expression is extensively found in SST-expressing cells. Reelin is also coexpressed in some of the CR-expressing cells.

Table 3. Interneuron-specific molecular markers in P21 mouse somatosensory cortex: Reelin expression in MGE-derived interneurons

\begin{tabular}{|c|c|c|c|c|c|c|c|}
\hline$\overline{\mathrm{MGE}}$ & & & & & & Non-MGE & \\
\hline SST+ & SST+/Reelin + & $\mathrm{EGFP}+/ \mathrm{SST}+$ & Triple+ & EGFP +/Reelin + & $\mathrm{EGFP}+$ & Reelin+ & Total \\
\hline $6.2 \%$ & $5.1 \%$ & $9.2 \%$ & $19.0 \%$ & $0 \%$ & $48.3 \%$ & $12.2 \%$ & 811 cells \\
\hline
\end{tabular}

All of MGE-derived interneurons (labeled with a method used in Table 1) expressing Reelin coexpress SST, suggesting that Reelin-positive SST-negative interneurons are exclusively derived from the CGE.
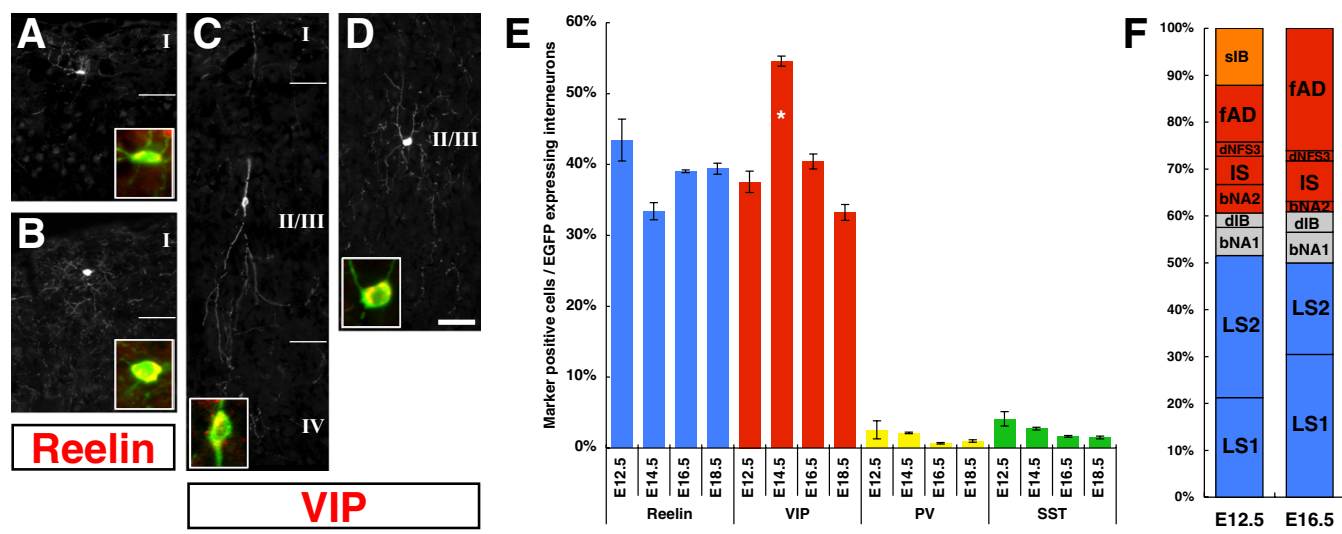

Figure 5. Reelin- and VIP-expressing interneurons originate from the CGE in relatively similar proportions between E12.5 and E18.5. A-D, Representative examples of Reelin-expressing multipolar cells $(\boldsymbol{A}, \boldsymbol{B})$ and VIP-expressing bipolar ( $\boldsymbol{C}$ ) and multipolar $(\boldsymbol{D})$ cells. $\boldsymbol{E}$, Histogram quantification of the percentage of CGE-derived interneurons at P21 fate mapped from E12.5, E14.5, E16.5 and E18.5 that express: Reelin, VIP, PV and SST. Reelin- and VIP-expressing interneurons are generated in a similar ratio ( $\sim 40 \%$ of production) from all developmental time points except at E14.5 ( $p=0.001$ ). At all time points examined, very few MGE-derived interneurons (PV- and SST-expressing) were observed. This suggests that most of the Reelin-expressing cells fate mapped do not coexpress SST. Error bars, SEM. F, The proportion of cortical interneuron subtypes generated at the onset (E12.5) and peak (E16.5) of the fate mapping of CGE-derived cortical interneurons. The sIB subtype was only found within the E12.5 fate mapped pool, and the fAD subtype was more prevalent following E16.5 labeling. Scale bar: $\boldsymbol{A}-\boldsymbol{D}, 50 \mu \mathrm{m}$.

found that Reelin- (Fig. 5A,B) and VIP- (Fig. 5C,D) expressing interneuron subtypes collectively comprise the majority of CGEderived populations at all time points that we assessed during development (Fig. $5 E$ ). With the exception of a small but significant peak in the generation of VIP-expressing neurons at E14.5 ( $p \leq$ 0.001 ), the ratio of the production of Reelin- versus VIPexpressing cells was similar. In accordance with these findings, our electrophysiological recordings of randomly sampled cells fate mapped from E12.5 $(n=33)$ and E16.5 $(n=46)$ yielded similar numbers of Reelin- and VIP-expressing interneuron subtypes (Fig. $5 F$ ).

\section{Physiologically and morphologically diverse subtypes of} cortical interneurons are derived from the CGE

Next, we performed a comprehensive electrophysiological and morphological analysis to determine the diversity of CGEderived interneurons. Similar to the approach taken in our previous studies, we generated acute brain slices of P14-P21 somatosensory cortex and analyzed fate-mapped interneurons expressing EGFP by whole-cell current-clamp analysis of intrinsic properties, combined with post hoc morphological and immunohistochemical analyses. In line with our previous efforts on the classification of interneurons we are introducing an electrophysiology-based naming system for CGE-derived interneurons that follows the Petilla convention (Ascoli et al., 2008) (also see note on interneuron nomenclature, Miyoshi et al., 2007). This resulted in the renaming of cell types we have previously reported (Butt et al., 2005; Miyoshi et al., 2007). We analyzed a total of 138 interneurons fate mapped from two time points (E12.5, $n=60$; E16.5, $n=78$ ). Consistent with our immunohistochemical analysis resulting in a small numbers of PVand SST-expressing interneurons (Fig. 5E), only a small fraction of fate mapped cells displayed firing patterns for MGE-derived subtypes (E12.5: $n=5$, E16.5: $n=8$ ) (Miyoshi et al., 2007). Based on our analysis we propose the existence of at least nine distinct subtypes (Fig. 6; Table 4).

The largest population of CGE-derived interneurons ( 50\%) was late spiking (LS). These can be subdivided into two subtypes LS1 (30\%) and LS2 (20\%), both of which expressed Reelin (3/6 and $4 / 6$ tested, respectively). Although the two LS subtypes shared many features, some aspects of their intrinsic firing properties and morphologies are distinct (see supplemental Fig. 4, available at www.jneurosci.org as supplemental material, for a detailed comparison). The LS1 subtype $(n=30)$ (no CRexpression, $0 / 4$ tested) was characterized by a pronounced delay of the threshold spike, preceded by a steady ramp depolarization, on a 500-ms-long square current pulse. Importantly, this delay persisted even when up to 3-5 spikes were induced. At more depolarized potentials these cells showed a pronounced adaptation in both firing frequency and spike height although the latter 


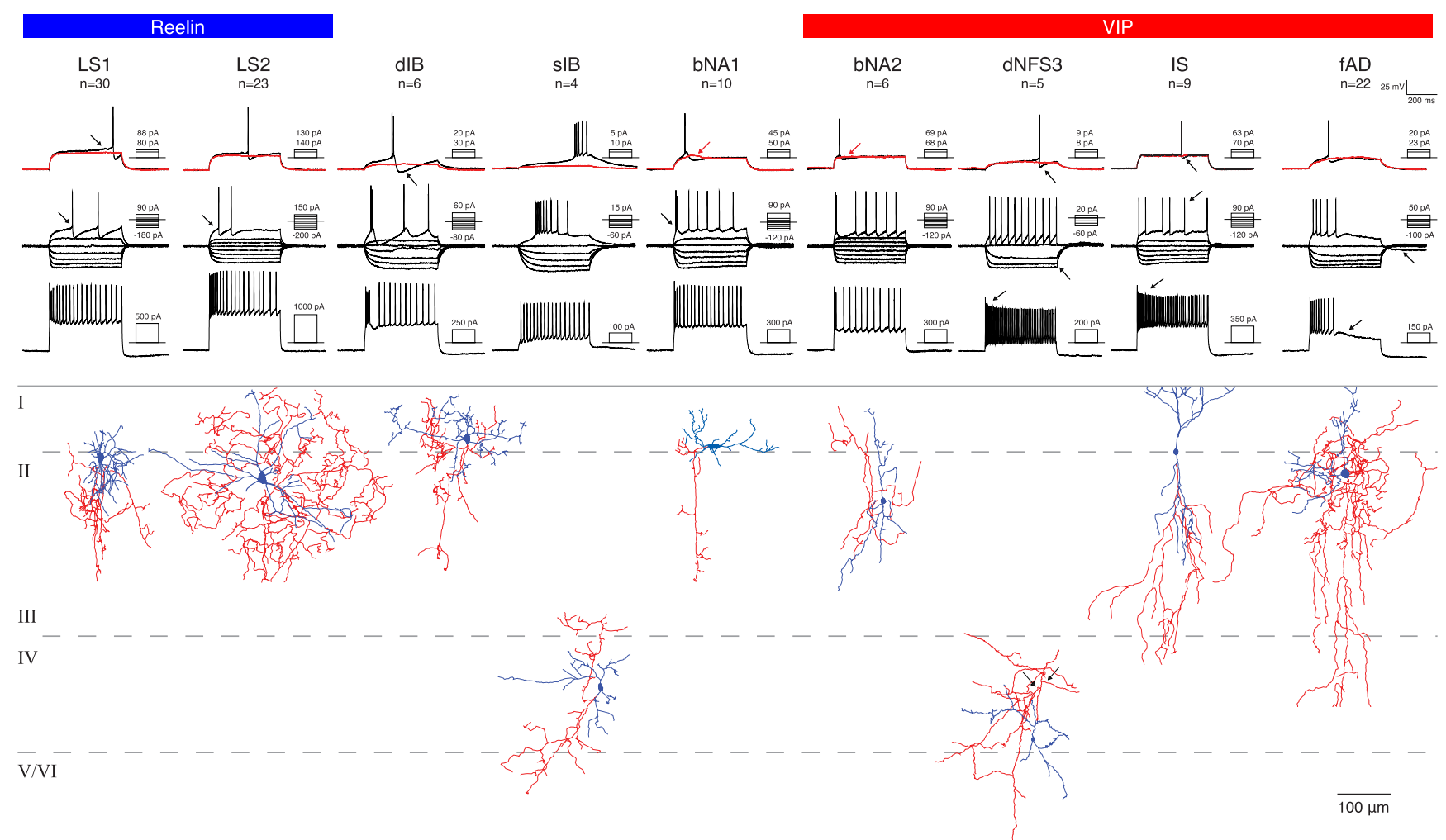

Figure 6. Nine subtypes of cortical interneurons with distinct intrinsic electrophysiological properties and morphologies are CGE-derived. CGE-derived cortical interneurons were characterized based on intrinsic electrophysiological properties and morphologies, and correlated with post hoc Reelin or VIP immunoreactivity. Top, Responses to 500 ms threshold (black trace) and below threshold (red trace) current injections (middle) responses to a hyperpolarizing current injection protocol (bottom) responses to a near maximum current injection. The LS1 (late-spiking) subtype shows a typical delayed threshold spike, a delay that persists during the firing of multiple spikes (arrows). The LS2 subtype often shows a delay to the threshold spike (top) but this delay is always eliminated at firing of more than one spike (arrow). The dIB (delayed intrinsic-bursting) subtype shows a bursting firing pattern from threshold with an AHP that typically goes below resting membrane potential of the cell (arrow). This subtype has a significant burst nonadapting (bNA) firing pattern, which persists at suprathreshold current injections (bottom). The sIB (sigmoid intrisic-bursting) subtype fires a 4-6 spike burst from threshold after a pronounced delay. The bNA1 (burst nonadapting) subtype shows a clear hump at near threshold levels early in the current injection (red arrow) and a biphasic AHP. The typical bNA pattern is seen at intermediate current injection (black arrow) of bNA1 subtype. The bNA2 subtype shows a pattern similar to that of bNA1, except for no hump in the beginning of the near threshold current injection (red arrow) and that the bNA-pattern typically persists at near maximum firing. The dNFS3 (delayed non-fast spiking) subtype shows a delay to the initial spike with a sigmoid shape and a sharp AHP (arrow in the top panel). All dNFS3 interneurons display rectification between hyperpolarizing steps (arrow in the middle panel) and a regular firing pattern with slight intraspike interval adaptation during intermediate current injections. The firing pattern of IS (irregular-spiking) subtype reveals a delay to the initial spike with subthreshold oscillations but it is not preceded by a ramp or a sigmoid shape. The shape of AHP is typically rounded (arrow in the top panel). The IS typically shows irregular firing during intermediate current injections (arrow in the middle panel) and a pronounced spike height adaptation throughout the suprathreshold current injection (arrow in the bottom panel). The fAD (fast-adapting) subtype fails to fire throughout the $500 \mathrm{~ms}$ current injection and show a hyperpolarization after the end of current injection (arrow in the middle panel). Note the slope of the trace after the spike train at intermediate (middle panel) and suprathreshold current injections (arrow in the bottom panel) for the fAD subtype. Bottom, Examples of morphological reconstructions by neurolucida tracing for each interneuron subtype. Dendrites are shown in blue and axon in red. The LS1 subtype exhibited the typical highly arborized dendritic pattern of neurogliaform cells while the LS2 subtype is generally larger and extends longer dendrites. The multipolar dIB subtypes were mainly found in superficial layers and often extended an axon toward deeper layers (similar to the bNA1). The bipolar sIB subtypes were found in deeper layers. The bNA2 subtypes have bipolar morphologies and were only recorded in layers II/III. Note the dNFS3 subtype showing a typical "axon arcade" morphology with an axon that starts out toward superficial layers from soma but the branches form arches when they project downward (arrows). The IS subtypes are bitufted with one dendritic branch reaching the pia and an axon extending deep while the fAD subtypes are bipolar/tripolar with an axon projecting locally as well as toward deeper layers. Numbers denote total cells recorded.

recovered later in the train. The cells were mostly located in layer I or on the I-II border (58\%), but were also found to lesser extents in layers II/III (15\%) and deeper layers (27\%). They all exhibited a dense dendritic tree with multiple branching points close to the soma, which morphologically resembled previous descriptions of cortical neurogliaform cells (Kawaguchi, 1995; Chu et al., 2003; Tamás et al., 2003; Miyoshi et al., 2007; Oláh et al., 2007). The LS2 subtype ( $n=23$ ) (CR-expression $2 / 4$ tested) had many features that resembled the LS1 subtype but never showed a delay to the first spike when firing two or more spikes. Compared with the LS1 subtype, the LS2 interneurons exhibited lower input resistance $(273.0 \pm 95.8$ vs $355.1 \pm 149.5 \mathrm{M} \Omega, p=0.015)$ as well as lower max firing frequency $(54.4 \pm 21.3$ vs $66.6 \pm 20.7 \mathrm{~Hz}, p=$ $0.010)$. The LS2 subtype had larger cell bodies and longer dendrites with fewer branch points close to the soma. They were found in all cortical layers but the majority $(65 \%)$ were located in layer I or on the I-II border (15\% and 20\% were located in layers II/III and deeper layers, respectively). These cells have previously been described as regular-spiking nonpyramidal (RSNP) or initial adapting (iAD) with a "dense plexus" multipolar morphology (Butt et al., 2005; Miyoshi et al., 2007). In our previous analysis using an Olig2-CreER driver, which predominantly labels cells emerging from the MGE, we obtained significant numbers of LS1 and LS2 (iAD) interneurons after E15.5 tamoxifen administration (Miyoshi et al., 2007). In that study, we speculated that these cells were of CGE origin since Olig2 expression is upregulated within the CGE by E15.5. This is now confirmed through the observation that both the LS1 and LS2 interneurons are the Reelin-positive, but SST-negative cell class, a molecular expression profile not found in cells that originate in the MGE (Fig. 4A). Interestingly, using similar genetic fate mapping approaches, hippocampal LS neurogliaform interneu- 
Table 4. Intrinsic electrophysiological properties of the nine distinct subtypes of CGE-derived cortical interneurons

\begin{tabular}{|c|c|c|c|c|c|c|c|c|c|}
\hline & $\begin{array}{l}\text { LS1 } \\
(n=26)\end{array}$ & $\begin{array}{l}\text { LS2 } \\
(n=19)\end{array}$ & $\begin{array}{l}\mathrm{dIB} \\
(n=5)\end{array}$ & $\begin{array}{l}\mathrm{sIB} \\
(n=3)\end{array}$ & $\begin{array}{l}\text { bNA1 } \\
(n=6)\end{array}$ & $\begin{array}{l}\text { bNA2 } \\
(n=5)\end{array}$ & $\begin{array}{l}\text { dNFS3 } \\
(n=5)\end{array}$ & $\begin{array}{l}\text { IS } \\
(n=6)\end{array}$ & $\begin{array}{l}\text { fAD } \\
(n=18)\end{array}$ \\
\hline $\mathrm{RMP}(\mathrm{mV})$ & $-64.5 \pm 6.0$ & $-64.5 \pm 6.7$ & $-61.8 \pm 8.7$ & $-68.8 \pm 5.8$ & $-67.4 \pm 3.9$ & $-61.5 \pm 4.4$ & $-63.7 \pm 5.9$ & $-54.0 \pm 4.6$ & $-57.7 \pm 8.5$ \\
\hline$R_{\text {in }}(\mathrm{M} \Omega)$ & $355.1 \pm 149.5$ & $273.0 \pm 95.8$ & $453.5 \pm 251.3$ & $587.0 \pm 305.9$ & $348.1 \pm 163.8$ & $387.5 \pm 171.2$ & $763.0 \pm 263.4$ & $468.0 \pm 165.2$ & $571.7 \pm 339.1$ \\
\hline Tau (ms) & $18.6 \pm 7.6$ & $18.3 \pm 6.2$ & $18.4 \pm 9.6$ & $18.0 \pm 11.4$ & $16.1 \pm 11.9$ & $18.9 \pm 5.5$ & $32.5 \pm 13.5$ & $19.2 \pm 4.0$ & $25.9 \pm 10.1$ \\
\hline Spike threshold (mV) & $-35.3 \pm 4.0$ & $-37.4 \pm 4.1$ & $-36.9 \pm 4.1$ & $-43.3 \pm 5.2$ & $-31.9 \pm 4.4$ & $-33.9 \pm 6.3$ & $-44.0 \pm 3.9$ & $-38.4 \pm 5.3$ & $-36.4 \pm 4.6$ \\
\hline Spike height (mV) & $65.5 \pm 7.9$ & $69.7 \pm 7.8$ & $59.9 \pm 8.4$ & $61.4 \pm 4.8$ & $64.3 \pm 11.1$ & $58.9 \pm 5.2$ & $68.1 \pm 13.4$ & $62.6 \pm 5.7$ & $62.7 \pm 7.5$ \\
\hline Spike width (ms) & $1.4 \pm 0.3$ & $1.4 \pm 0.2$ & $1.3 \pm 0.3$ & $1.4 \pm 0.5$ & $1.4 \pm 0.3$ & $1.5 \pm 0.3$ & $1.0 \pm 0.1$ & $0.9 \pm 0.2$ & $1.0 \pm 0.2$ \\
\hline AHP $T_{\text {nadir }}$ (ms) & $21.3 \pm 5.4$ & $25.7 \pm 11.9$ & $74.3 \pm 18.0$ & $15.5 \pm 4.6$ & $63.2 \pm 15.5$ & $26.8 \pm 8.3$ & $12.5 \pm 11.2$ & $15.2 \pm 3.1$ & $19.0 \pm 11.9$ \\
\hline AHP amplitude (mV) & $-17.1 \pm 4.7$ & $-15.1 \pm 4.1$ & $-18.5 \pm 4.7$ & $-6.6 \pm 1.9$ & $-16.3 \pm 6.1$ & $-12.7 \pm 2.5$ & $-14.2 \pm 2.3$ & $-11.1 \pm 3.1$ & $-9.8 \pm 2.3$ \\
\hline Delay to spike (ms) & $348.6 \pm 104.6$ & $174.8 \pm 117.7$ & $208.7 \pm 141.9$ & $245.8 \pm 103.0$ & $62.4 \pm 15.2$ & $90.5 \pm 58.9$ & $286.4 \pm 137.5$ & $303.8 \pm 71.6$ & $192.4 \pm 127.7$ \\
\hline Max frequency $(\mathrm{Hz})$ & $66.6 \pm 20.7$ & $54.4 \pm 21.3$ & $63.2 \pm 40.0$ & $82.0 \pm 28.3$ & $40.0 \pm 18.4$ & $48.4 \pm 16.6$ & $78.4 \pm 19.9$ & $77.7 \pm 22.5$ & $76.6 \pm 26.6$ \\
\hline Adaptation & $46.8 \pm 19.8 \%$ & $58.0 \pm 15.7 \%$ & $41.9 \pm 17.2 \%$ & $45.4 \pm 11.2 \%$ & $72.2 \pm 10.6 \%$ & $58.9 \pm 20.5 \%$ & $31.8 \pm 7.7 \%$ & $39.5 \pm 11.6 \%$ & $\mathrm{~N} / \mathrm{A}$ \\
\hline$I_{\mathrm{h}} / \mathrm{sag}(\mathrm{mV})$ & $2.1 \pm 1.5$ & $2.3 \pm 1.8$ & $1.3 \pm 1.5$ & $2.7 \pm 1.5$ & $1.5 \pm 1.9$ & $3.8 \pm 3.8$ & $0.7 \pm 0.9$ & $4.4 \pm 3.6$ & $6.8 \pm 3.8$ \\
\hline Subthreshold.osc & $Y$ & $Y$ & $\mathrm{~N}$ & $\mathrm{~N}$ & $\mathrm{~N}$ & $\mathrm{~N}$ & $\mathrm{~N}$ & $Y$ & $\mathrm{~N}$ \\
\hline
\end{tabular}

Values are mean \pm SD. Subthreshold osc, subthreshold oscillations; $Y$, yes; $N$, no.

rons appear to have a dual origin, with a subpopulation being MGEderived (G. Fishell, C. McBain, unpublished observations).

The majority of CGE-derived interneurons that do not express Reelin express VIP (Figs. 4A, 5E). In our fate mapping study, the largest class of VIP-expressing interneurons is comparable in number to the two Reelin-expressing subtypes of LS1 and LS2 ( 25\%). This VIP-expressing subtype is characterized by a fast sizeable adaptation leading to an inability to fire throughout the $500 \mathrm{~ms}$ current injection. We therefore refer to these neurons as fast-adapting (fAD) cells ( $3 / 3$ and $0 / 3$ tested for VIP and CR, respectively) [previously referred to as "rAD" (Butt et al., 2005)]. The fAD interneurons are electrically small and fire spikes with relatively short half-width $(1.0 \pm 0.2 \mathrm{~ms})$ and are located mainly in layer II/III (63\%, the remainder were located within the I-II border [32\%] and in deeper layers [6\%]). They had bipolar/tripolar morphology with dendrites stretching toward the pia, and an axon that branched close to the cell soma, as well as extending into deeper layers.

In addition to the three major subtypes described above (that in total accounted for $\sim 75 \%$ of all CGE-derived interneurons), we identified another six classes of interneurons that possess distinct firing properties and morphologies (see supplemental material, available at www.jneurosci.org, for description of the detailed intrinsic firing properties of these six subtypes). Of these, the irregular-spiking (IS) subtype (Butt et al., 2005) was the most prominent, comprising $\sim 10 \%$ of all CGE-derived interneurons. The IS subtype is VIP- and CR-expressing (3/4 and 3/5 tested, respectively) and bipolar/tripolar in morphology. We also found one subtype with intrinsic firing properties similar to MGEderived SST-expressing delayed non-fast spiking interneurons (dNFS1 and dNFS2) (Miyoshi et al., 2007) that we named dNFS3. The dNFS3 subtype had a distinct axon-arcade morphology and has previously been described as VIP-positive (Kawaguchi and Kubota, 1996; Butt et al., 2005).

We also recorded two intrinsic-bursting subtypes (delayed and sigmoid; $\mathrm{dIB}$ and SIB, respectively), which exhibited a burst of action potentials (APs) at threshold. These subtypes were distinct from the previously described MGE-derived intrinsic or rebound bursting classes (iIB and rIB respectively) (Miyoshi et al., 2007). Interestingly, the dIB subtype had a firing pattern that strongly resembles that of another multipolar layer II cell described as PV and calbindin (CB) positive but CR negative (Blatow et al., 2003). The last two subtypes we found were burst nonadapting (bNA1 and bNA2) cells, which fired a burst of APs above but not at threshold. The bNA2 subtype had morphologies and firing patterns that resembled previously described VIPexpressing cell types (Butt et al., 2005; Caputi et al., 2009; Kawaguchi and Kubota, 1996; Rozov et al., 2001) (2/4 and 2/5 bNA2 cells were positive for VIP and CR, respectively). Together, these data suggest that an equivalent degree of diversity exists within MGE- and CGE-derived interneurons. Hence, to date the total population of CGE-derived interneurons has been both quantitatively, as well as qualitatively underestimated.

\section{Discussion}

Our analysis of CGE-derived cortical interneurons revealed that both the initiation and peak production of CGE-derived interneurons occur several days later in development than that observed in MGE-derived populations. Moreover, unlike interneurons derived from the MGE, which are born in an inside-out manner, CGE-derived interneurons preferentially contribute to the superficial cortical layers regardless of their birthdate. We also demonstrated that the populations of cortical interneurons arising from the CGE are both considerably larger in number and greater in diversity than previously appreciated. This in part is because both the molecular markers for, and the origins of some prominent CGE-derived interneuron subtypes, such as the neurogliaform subclass, had not been determined previously. Our present findings indicate that a large percentage of the interneurons whose origins were unaccounted for are derived from the CGE and express the glycoprotein Reelin. With this finding, the majority of cortical interneurons $(\sim 95 \%)$ can be assigned to one of four nonoverlapping molecular markers: PV, SST, Reelin (without SST) and VIP. Therefore, all major subclasses of cortical interneurons can now be assigned to either MGE- or CGEderived lineages.

\section{Do cortical interneurons solely originate from the MGE and the CGE?}

The original observation that cortical interneurons are ventrally derived suggested that the LGE might be a source of these cells (Anderson et al., 1997). However, in vivo fate mapping using transplantation of genetically marked donor tissues argued against this interpretation (Wichterle et al., 2001). This later work indicated that at least at E13.5, while the MGE produced large numbers of cortical interneurons, the LGE produced few if any. However, a caveat to this conclusion is that this study restricted itself to a single, relatively early developmental time point. Complicating matters further, significant numbers of MGE-derived cortical interneurons migrate through the LGE (Wichterle et al., 2001) at 
later developmental stages. This contamination precluded this approach from being a useful method for resolving this issue.

The possibility that the LGE contributes to cortical interneuron production was again suggested by subsequent analysis by our laboratory and others that indicated the CGE provided an additional source of cortical interneurons (Nery et al., 2002; Xu et al., 2004; Butt et al., 2005). The close molecular resemblance between the CGE and LGE raised the question as to whether at later developmental time points the LGE might also generate a subpopulation of cortical interneurons. Indeed, one group has gone so far as to argue that the CGE might be better classified as a caudal extension of the LGE (Flames et al., 2007).

Since the Mash1BAC-CreER driver line we used in this study labeled precursors arising from the LGE, as well as the CGE, and given that the "CGE-derived" population was larger, more diverse and originated considerably later than previously recognized, it seems reasonable to consider the possibility that some cortical interneurons are LGE-derived. While we cannot entirely rule this out, a number of circumstantial observations suggest that the vast majority of the cortical interneurons fate mapped in this study are truly derived from the CGE. First, our analysis of short-term fate mapping revealed the migration of cells toward the cortex at CGE but not LGE-levels of the telencephalon. Second, $84.6 \%$ of the fate-mapped cells expressed CoupTFII as they migrate tangentially. During embryogenesis, CoupTFII is almost exclusively confined to the CGE, with only sparse expression within the LGE (Kanatani et al., 2008; Willi-Monnerat et al., 2008). In addition, this expression might well represent migration of CGE-derived cells rostrally through the LGE. Assuming that the expression of this protein is not dynamic, one could infer that the overwhelming majority of cortical interneurons we observe arise solely from the CGE. Inducible genetic fate mapping of CoupTFII-expressing cells would no doubt help to definitively resolve this issue.

Assuming that the MGE and CGE generate the majority of cortical interneurons, is there reason to believe that additional sources of cortical interneurons remain to be identified? In this regard, a recent study demonstrated that genetic fate mapping of Nkx5-1-expressing cells confined to the preoptic area (POA) resulted in the labeling of a relatively small population of cortical interneurons, 30\% of which expressed NPY (Gelman et al., 2009). As Nkx5-1 expression is confined to a subregion of the POA, additional cortical interneuron populations could possibly arise from this structure as well. In addition, a number of regions of the ventral, and possibly dorsal (Letinic et al., 2002) telencephalon may ultimately prove to be a source for subpopulations of cortical interneurons. This aside, comparing both the numbers and the diversity of cortical interneuron populations that can be attributed to arise from the MGE (Miyoshi et al., 2007) and the CGE (the present study), additional sources likely account for $<5 \%$ of the total cortical interneuron population.

\section{The role of spatial and temporal cues in the generation of CGE-derived interneuron subtypes}

Previous analysis has suggested that subtype diversity within MGE-derived interneurons may arise from either spatial or temporal constraints. Recent work has shown that the presumptive PV-expressing basket cells arise preferentially in the ventral MGE, while SST-expressing Martinotti cells are produced in greater number in the dorsal MGE (Flames et al., 2007; Fogarty et al., 2007; Ghanem et al., 2007; Wonders et al., 2008). It has been shown that MGE-derived interneurons are born in an inside-out manner, suggesting that cortical interneuron diversity may be linked to their time of origin (Xu et al., 2004; Yozu et al., 2004; Miyoshi et al., 2007; Rymar and Sadikot, 2007). Indeed, our recent electrophysiological analysis of MGE-derived interneuron subtypes supports this notion by showing that different subtypes are generated at distinct developmental stages (Miyoshi et al., 2007). Together, these findings suggest that the diversity of MGEderived interneurons might be generated both by spatially distinct progenitor pools that are restricted to give rise to only certain subtypes, as well as temporal changes in their specification programs within these progenitor pools.

What then is the mechanism for generating diverse subtypes of interneurons derived from the CGE? CGE-derived interneurons, which are comprised largely by Reelin- and VIP-expressing (Cavanagh and Parnavelas, 1989) subtypes, are not generated in an inside-out manner but rather show a preference for superficial cortical layers regardless to their birthdates. These findings appear to support the notion that temporal changes in the production of different CGE-derived subtypes is less prominent than in the MGE. The observation that the ratio of Reelin- versus VIPexpressing cortical interneurons is largely maintained throughout development seems to support this idea. This, however, is somewhat misleading, as fine-grained electrophysiological analysis suggests that while sIB interneurons are only found in the earliest born CGE-derived subtypes, fAD interneurons are preferentially produced at the peak of interneuron production (This study and Butt et al., 2005). Even so, the temporal shifts in CGEderived interneuron subtypes do appear on the whole to be less pronounced than what is observed in the MGE. It is intriguing to speculate as to whether the shift in the production of particular interneuron subtypes represents temporal alterations in the potential of progenitors or shifts in the instructive cues within the cortex as development progresses. However, only by experimentally challenging CGE-derived interneurons through approaches such as heterochronic transplantation can this question be properly addressed.

In summary, by taking advantage of an inducible genetic fate mapping strategy in combination with electrophysiological recordings of intrinsic properties, we have examined the temporal production and mature diversity of cortical interneurons generated from the CGE (and possibly the LGE). In the process we have determined that the CGE is considerably more robust in its contribution to cortical interneuron diversity than previously realized. Thus the present work, together with our previous fate mapping study on the MGE, demonstrates that CGE-derived interneurons possess both cellular characteristics and laminar specificities that are distinct from those of the populations derived from the MGE. Hence, through the use of these developmental genetics approaches, we have been able to determine the spatial and temporal origins of all major classes of cortical interneurons.

\section{References}

Alcántara S, Ruiz M, D’Arcangelo G, Ezan F, de Lecea L, Curran T, Sotelo C, Soriano E (1998) Regional and cellular patterns of reelin mRNA expression in the forebrain of the developing and adult mouse. J Neurosci 18:7779-7799.

Anderson SA, Eisenstat DD, Shi L, Rubenstein JL (1997) Interneuron migration from basal forebrain to neocortex: dependence on Dlx genes. Science 278:474-476.

Angevine JB II, Sidman RL (1961) Autoradiographic study of cell migration during histogenesis of cerebral cortex in the mouse. Nature 192:766-768.

Ascoli GA, Alonso-Nanclares L, Anderson SA, Barrionuevo G, BenavidesPiccione R, Burkhalter A, Buzsáki G, Cauli B, Defelipe J, Fairén A, Feldmeyer D, Fishell G, Fregnac Y, Freund TF, Gardner D, Gardner EP, Goldberg JH, Helmstaedter M, Hestrin S, Karube F, et al. (2008) Petilla 
terminology: nomenclature of features of GABAergic interneurons of the cerebral cortex. Nat Rev Neurosci 9:557-568.

Bai CB, Auerbach W, Lee JS, Stephen D, Joyner AL (2002) Gli2, but not Gli1, is required for initial Shh signaling and ectopic activation of the Shh pathway. Development 129:4753-4761.

Balordi F, Fishell G (2007) Mosaic removal of hedgehog signaling in the adult SVZ reveals that the residual wild-type stem cells have a limited capacity for self-renewal. J Neurosci 27:14248-14259.

Battiste J, Helms AW, Kim EJ, Savage TK, Lagace DC, Mandyam CD, Eisch AJ, Miyoshi G, Johnson JE (2007) Ascll defines sequentially generated lineage-restricted neuronal and oligodendrocyte precursor cells in the spinal cord. Development 134:285-293.

Bertrand N, Castro DS, Guillemot F (2002) Proneural genes and the specification of neural cell types. Nat Rev Neurosci 3:517-530.

Blatow M, Rozov A, Katona I, Hormuzdi SG, Meyer AH, Whittington MA, Caputi A, Monyer H (2003) A novel network of multipolar bursting interneurons generates theta frequency oscillations in neocortex. Neuron 38:805-817.

Branda CS, Dymecki SM (2004) Talking about a revolution: the impact of site-specific recombinases on genetic analyses in mice. Dev Cell 6:7-28.

Britz O, Mattar P, Nguyen L, Langevin LM, Zimmer C, Alam S, Guillemot F, Schuurmans C (2006) A role for proneural genes in the maturation of cortical progenitor cells. Cereb Cortex 16 [Suppl 1]:i138-i151.

Butt SJ, Fuccillo M, Nery S, Noctor S, Kriegstein A, Corbin JG, Fishell G (2005) The temporal and spatial origins of cortical interneurons predict their physiological subtype. Neuron 48:591-604.

Butt SJ, Sousa VH, Fuccillo MV, Hjerling-Leffler J, Miyoshi G, Kimura S, Fishell G (2008) The requirement of Nkx2-1 in the temporal specification of cortical interneuron subtypes. Neuron 59:722-732.

Caputi A, Rozov A, Blatow M, Monyer H (2009) Two calretinin-positive GABAergic cell types in layer $2 / 3$ of the mouse neocortex provide different forms of inhibition. Cereb Cortex 19:1345-1359.

Casarosa S, Fode C, Guillemot F (1999) Mash1 regulates neurogenesis in the ventral telencephalon. Development 126:525-534.

Cavanagh ME, Parnavelas JG (1989) Development of vasoactive-intestinalpolypeptide-immunoreactive neurons in the rat occipital cortex: a combined immunohistochemical-autoradiographic study. J Comp Neurol 284:637-645.

Chu Z, Galarreta M, Hestrin S (2003) Synaptic interactions of late-spiking neocortical neurons in layer 1. J Neurosci 23:96-102.

Cobos I, Calcagnotto ME, Vilaythong AJ, Thwin MT, Noebels JL, Baraban SC, Rubenstein JL (2005) Mice lacking Dlx1 show subtype-specific loss of interneurons, reduced inhibition and epilepsy. Nat Neurosci 8:10591068.

Corbin JG, Nery S, Fishell G (2001) Telencephalic cells take a tangent: nonradial migration in the mammalian forebrain. Nat Neurosci 4 [Suppl]:1177-1182.

Cubelos B, Sebastián-Serrano A, Kim S, Redondo JM, Walsh C, Nieto M (2008) Cux-1 and Cux-2 control the development of Reelin expressing cortical interneurons. Dev Neurobiol 68:917-925.

del Río JA, Martínez A, Fonseca M, Auladell C, Soriano E (1995) Glutamatelike immunoreactivity and fate of Cajal-Retzius cells in the murine cortex as identified with calretinin antibody. Cereb Cortex 5:13-21.

Derer P, Derer M (1990) Cajal-Retzius cell ontogenesis and death in mouse brain visualized with horseradish peroxidase and electron microscopy. Neuroscience 36:839-856.

Du T, Xu Q, Ocbina PJ, Anderson SA (2008) NKX2.1 specifies cortical interneuron fate by activating Lhx6. Development 135:1559-1567.

Emson PC, Gilbert RF, Loren I, Fahrenkrug J, Sundler F, Schaffalitzky de Muckadell OB (1979) Development of vasoactive intestinal polypeptide (VIP) containing neurones in the rat brain. Brain Res 177:437-444.

Fairén A, Cobas A, Fonseca M (1986) Times of generation of glutamic acid decarboxylase immunoreactive neurons in mouse somatosensory cortex. J Comp Neurol 251:67-83.

Farago AF, Awatramani RB, Dymecki SM (2006) Assembly of the brainstem cochlear nuclear complex is revealed by intersectional and subtractive genetic fate maps. Neuron 50:205-218.

Flames N, Pla R, Gelman DM, Rubenstein JL, Puelles L, Marín O (2007) Delineation of multiple subpallial progenitor domains by the combinatorial expression of transcriptional codes. J Neurosci 27:9682-9695.

Fode C, Ma Q, Casarosa S, Ang SL, Anderson DJ, Guillemot F (2000) A role for neural determination genes in specifying the dorsoventral identity of telencephalic neurons. Genes Dev 14:67-80.

Fogarty M, Grist M, Gelman D, Marín O, Pachnis V, Kessaris N (2007) Spatial genetic patterning of the embryonic neuroepithelium generates GABAergic interneuron diversity in the adult cortex. J Neurosci 27:10935-10946.

Gelman DM, Martini FJ, Nóbrega-Pereira S, Pierani A, Kessaris N, Marín O (2009) The embryonic preoptic area is a novel source of cortical GABAergic interneurons. J Neurosci 29:9380-9389.

Ghanem N, Yu M, Long J, Hatch G, Rubenstein JL, Ekker M (2007) Distinct cis-regulatory elements from the Dlx1/Dlx2 locus mark different progenitor cell populations in the ganglionic eminences and different subtypes of adult cortical interneurons. J Neurosci 27:5012-5022.

Guillemot F, Joyner AL (1993) Dynamic expression of the murine AchaeteScute homologue Mash-1 in the developing nervous system. Mech Dev 42:171-185.

Hammond V, Tsai LH, Tan SS (2004) Control of cortical neuron migration and layering: cell and non cell-autonomous effects of p35. J Neurosci 24:576-587.

Horton S, Meredith A, Richardson JA, Johnson JE (1999) Correct coordination of neuronal differentiation events in ventral forebrain requires the bHLH factor MASH1. Mol Cell Neurosci 14:355-369.

Johnson JE, Birren SJ, Anderson DJ (1990) Two rat homologues of Drosophila Achaete-Scute specifically expressed in neuronal precursors. Nature 346:858-861.

Kanatani S, Yozu M, Tabata H, Nakajima K (2008) COUP-TFII is preferentially expressed in the caudal ganglionic eminence and is involved in the caudal migratory stream. J Neurosci 28:13582-13591.

Kawaguchi Y (1995) Physiological subgroups of nonpyramidal cells with specific morphological characteristics in layer II/III of rat frontal cortex. J Neurosci 15:2638-2655.

Kawaguchi Y, Kubota Y (1996) Physiological and morphological identification of somatostatin- or vasoactive intestinal polypeptide-containing cells among GABAergic cell subtypes in rat frontal cortex. J Neurosci 16:2701-2715.

Kill IR (1996) Localisation of the Ki-67 antigen within the nucleolus. Evidence for a fibrillarin-deficient region of the dense fibrillar component. J Cell Sci 109:1253-1263.

Kriegstein AR, Noctor SC (2004) Patterns of neuronal migration in the embryonic cortex. Trends Neurosci 27:392-399.

Kubota Y, Hattori R, Yui Y (1994) Three distinct subpopulations of GABAergic neurons in rat frontal agranular cortex. Brain Res 649:159-173

Letinic K, Zoncu R, Rakic P (2002) Origin of GABAergic neurons in the human neocortex. Nature 417:645-649.

Marín O, Rubenstein JL (2003) Cell migration in the forebrain. Annu Rev Neurosci 26:441-483.

Markram H, Toledo-Rodriguez M, Wang Y, Gupta A, Silberberg G, Wu C (2004) Interneurons of the neocortical inhibitory system. Nat Rev Neurosci 5:793-807.

Meyer G, Soria JM, Martínez-Galán JR, Martín-Clemente B, Fairén A (1998) Different origins and developmental histories of transient neurons in the marginal zone of the fetal and neonatal rat cortex. J Comp Neurol 397:493-518.

Miller MW (1985) Cogeneration of retrogradely labeled corticocortical projection and GABA-immunoreactive local circuit neurons in cerebral cortex. Brain Res 355:187-192.

Miyoshi G, Fishell G (2006) Directing neuron-specific transgene expression in the mouse CNS. Curr Opin Neurobiol 16:577-584.

Miyoshi G, Butt SJ, Takebayashi H, Fishell G (2007) Physiologically distinct temporal cohorts of cortical interneurons arise from telencephalic Olig2expressing precursors. J Neurosci 27:7786-7798.

Nery S, Fishell G, Corbin JG (2002) The caudal ganglionic eminence is a source of distinct cortical and subcortical cell populations. Nat Neurosci 5:1279-1287.

Niwa H, Yamamura K, Miyazaki J (1991) Efficient selection for highexpression transfectants with a novel eukaryotic vector. Gene 108:193-199.

Ogawa M, Miyata T, Nakajima K, Yagyu K, Seike M, Ikenaka K, Yamamoto H, Mikoshiba K (1995) The reeler gene-associated antigen on CajalRetzius neurons is a crucial molecule for laminar organization of cortical neurons. Neuron 14:899-912. 
Oláh S, Komlósi G, Szabadics J, Varga C, Tóth E, Barzó P, Tamás G (2007) Output of neurogliaform cells to various neuron types in the human and rat cerebral cortex. Front Neural Circuits 1:4.

Parras CM, Schuurmans C, Scardigli R, Kim J, Anderson DJ, Guillemot F (2002) Divergent functions of the proneural genes Mash1 and Ngn2 in the specification of neuronal subtype identity. Genes Dev 16:324-338.

Parras CM, Hunt C, Sugimori M, Nakafuku M, Rowitch D, Guillemot F (2007) The proneural gene Mash1 specifies an early population of telencephalic oligodendrocytes. J Neurosci 27:4233-4242.

Pesold C, Impagnatiello F, Pisu MG, Uzunov DP, Costa E, Guidotti A, Caruncho HJ (1998) Reelin is preferentially expressed in neurons synthesizing gamma-aminobutyric acid in cortex and hippocampus of adult rats. Proc Natl Acad Sci U S A 95:3221-3226.

Pesold C, Liu WS, Guidotti A, Costa E, Caruncho HJ (1999) Cortical bitufted, horizontal, and Martinotti cells preferentially express and secrete reelin into perineuronal nets, nonsynaptically modulating gene expression. Proc Natl Acad Sci U S A 96:3217-3222.

Rodríguez CI, Buchholz F, Galloway J, Sequerra R, Kasper J, Ayala R, Stewart AF, Dymecki SM (2000) High-efficiency deleter mice show that FLPe is an alternative to Cre-loxP. Nat Genet 25:139-140.

Rogers JH (1992) Immunohistochemical markers in rat cortex: colocalization of calretinin and calbindin-D28k with neuropeptides and GABA. Brain Res 587:147-157.

Rozov A, Jerecic J, Sakmann B, Burnashev N (2001) AMPA receptor channels with long-lasting desensitization in bipolar interneurons contribute to synaptic depression in a novel feedback circuit in layer $2 / 3$ of rat neocortex. J Neurosci 21:8062-8071.

Rymar VV, Sadikot AF (2007) Laminar fate of cortical GABAergic interneurons is dependent on both birthdate and phenotype. J Comp Neurol 501:369-380.

Soriano P (1999) Generalized lacZ expression with the ROSA26 Cre reporter strain. Nat Genet 21:70-71.

Srinivas S, Watanabe T, Lin CS, William CM, Tanabe Y, Jessell TM, Costantini F (2001) Cre reporter strains produced by targeted insertion of EYFP and ECFP into the ROSA26 locus. BMC Dev Biol 1:4.

Stenman J, Toresson H, Campbell K (2003) Identification of two distinct progenitor populations in the lateral ganglionic eminence: implications for striatal and olfactory bulb neurogenesis. J Neurosci 23:167-174.

Sussel L, Marin O, Kimura S, Rubenstein JL (1999) Loss of Nkx2.1 homeobox gene function results in a ventral to dorsal molecular respecifi- cation within the basal telencephalon: evidence for a transformation of the pallidum into the striatum. Development 126:3359-3370.

Tamamaki N, Yanagawa Y, Tomioka R, Miyazaki J, Obata K, Kaneko T (2003) Green fluorescent protein expression and colocalization with calretinin, parvalbumin, and somatostatin in the GAD67-GFP knock-in mouse. J Comp Neurol 467:60-79.

Tamás G, Lorincz A, Simon A, Szabadics J (2003) Identified sources and targets of slow inhibition in the neocortex. Science 299:1902-1905.

Wichterle H, Turnbull DH, Nery S, Fishell G, Alvarez-Buylla A (2001) In utero fate mapping reveals distinct migratory pathways and fates of neurons born in the mammalian basal forebrain. Development 128:37593771.

Willi-Monnerat S, Migliavacca E, Surdez D, Delorenzi M, Luthi-Carter R, Terskikh AV (2008) Comprehensive spatiotemporal transcriptomic analyses of the ganglionic eminences demonstrate the uniqueness of its caudal subdivision. Mol Cell Neurosci 37:845-856.

Wonders CP, Anderson SA (2006) The origin and specification of cortical interneurons. Nat Rev Neurosci 7:687-696.

Wonders CP, Taylor L, Welagen J, Mbata IC, Xiang JZ, Anderson SA (2008) A spatial bias for the origins of interneuron subgroups within the medial ganglionic eminence. Dev Biol 314:127-136.

Xu Q, Cobos I, De La Cruz E, Rubenstein JL, Anderson SA (2004) Origins of cortical interneuron subtypes. J Neurosci 24:2612-2622.

Xu Q, Tam M, Anderson SA (2008) Fate mapping Nkx2.1-lineage cells in the mouse telencephalon. J Comp Neurol 506:16-29.

Yozu M, Tabata H, Nakajima K (2004) Birth-date dependent alignment of GABAergic neurons occurs in a different pattern from that of nonGABAergic neurons in the developing mouse visual cortex. Neurosci Res 49:395-403.

Yun K, Fischman S, Johnson J, Hrabe de Angelis M, Weinmaster G, Rubenstein JL (2002) Modulation of the notch signaling by Mash1 and Dlx1/2 regulates sequential specification and differentiation of progenitor cell types in the subcortical telencephalon. Development 129:5029-5040.

Zerucha T, Stühmer T, Hatch G, Park BK, Long Q, Yu G, Gambarotta A, Schultz JR, Rubenstein JL, Ekker M (2000) A highly conserved enhancer in the Dlx5/Dlx6 intergenic region is the site of cross-regulatory interactions between Dlx genes in the embryonic forebrain. J Neurosci 20:709-721.

Zervas M, Millet S, Ahn S, Joyner AL (2004) Cell behaviors and genetic lineages of the mesencephalon and rhombomere 1. Neuron 43:345-357.

Zong H, Espinosa JS, Su HH, Muzumdar MD, Luo L (2005) Mosaic analysis with double markers in mice. Cell 121:479-492. 